\title{
A Mathematical Model for Zeolite Membrane Module Performance and its Use for Techno-Economic Evaluation of Improved Energy Efficiency Hybrid Membrane- Distillation Processes for Butane Isomer Separations
}

Nitish Mittal ${ }^{1}$, Peng Bai ${ }^{1}$, Adam Kelloway ${ }^{1}$, J. Ilja Siepmann ${ }^{1,2}$, Prodromos Daoutidis ${ }^{1}$, Michael Tsapatsis $^{1 *}$

${ }^{1}$ Department of Chemical Engineering and Materials Science, University of Minnesota, 421 Washington Avenue SE, Minneapolis, Minnesota 55455, USA

${ }^{2}$ Department of Chemistry, University of Minnesota, 207 Pleasant Street SE, Minneapolis, Minnesota 55455, USA

* E-mail: tsapa001@umn.edu 


\begin{abstract}
:
The aim of this work is to develop enabling tools that can assess the potential of zeolite membranes for industrial applications. The specific objectives are: (1) Develop a detailed mathematical model of a zeolite membrane separation process for accurate performance prediction under industrial conditions, and (2) Perform conceptual process design and technoeconomic evaluation of the overall process for an application specific flowsheet. To this end, a detailed mathematical model, based on the real adsorption solution (RAS) theory and the Maxwell-Stefan formulation for transport was developed to describe permeation through a zeolite membrane. Effects like support resistances to transport, use of sweep gas and concentration polarization were included. The model is further applied to study butane isomer separation using a MFI-type zeolite membrane. A comparison of steady state flux and separation factor predicted by the model with the experimentally determined values suggests that the permeation in the real membranes is lower than that for the zeolite crystals. This lower permeance is attributed to the microstructural defects and suggests that there is a considerable scope of improvement in the performance of current state-of-the-art real MFI membranes. It is shown that up to a 10-fold increase in permeance through the membrane is practical, beyond which the external resistance starts to dominate. Furthermore, the detailed zeolite membrane model is integrated into a process level simulation, to evaluate the membrane performance in industrial settings and a techno-economic analysis is also performed to this end. While single stage membrane process does not achieve the target purity and multi-stage membrane process requires prohibitively large area, a hybrid membrane/distillation process is found to be energy efficient and economically attractive.
\end{abstract}




\section{Introduction}

Zeolite membranes offer an attractive alternative to conventional energy intensive separation processes [1-5]. Their chemical and thermal stability, and well-defined pore structure with pore sizes ranging from 0.3-1.0 $\mathrm{nm}$ allow for high-selectivity separations at a wide range of operating conditions. Although zeolite membranes have shown remarkable progress at laboratory scale [614] and promising results have been obtained for various industrially relevant applications such as alcohol dehydration [12,15-18], butane isomer separation [11,19-23], xylene isomer separation [20-23] and natural gas purification [24-27], only hydrophilic membranes used in the dehydration of industrial solvents have been commercialized to date $[5,13]$. To explore the commercialization potential of zeolite membranes, rigorous models and process designs which can predict the currently achieved performance and set targets for membrane cost and performance improvements are essential.

In order to predict the separation performance of zeolite membranes, a fundamental understanding of transport phenomena underlying the membrane operation, and models that can quantitatively describe these phenomena, are necessary. Permeation through a zeolite membrane is a complex process that depends on both the adsorption and diffusion properties of the permeating species in the mixture [8,15,28-34]. When the size of the molecules permeating through the zeolite pores is comparable to the pore diameter, which is often the case for selective separation, molecules permeate at a regime commonly known as intracrystalline or configurational diffusion. The adsorption and diffusion properties at this microscopic level are obtained using experimental and simulation techniques, fitted to adsorption and diffusion models, and then finally used in continuum models to determine the flux through the zeolite membranes. While most modeling studies employ simple ideal theories based on single-component adsorption and diffusion properties [35-40], the intermolecular interactions can be far from ideal and may lead to the failure of these theories [41-47]. 
In addition to the adsorption and diffusion based transport through zeolite layer, factors such as mass transfer through the porous support, the use of a sweep gas and the concentration polarization phenomenon can also play a significant role [13]. The support is particularly important for membranes with thin zeolite films as the resistance of the support layer can dominate the transport through the membrane $[16,37,48,49]$. The use of sweep gas increases the driving force for permeation by carrying away permeating species. In most of the modeling studies aiming at interpretation of laboratory results, this effect is incorporated by assuming zero partial pressure of the permeating species on the permeate side [42,50,51]. However, even a low value of partial pressure can significantly affect the performance, especially for strongly adsorbing components where significant changes in loading occurs even at pressure below 1 mbar [52-54]. Moreover, there is also an adverse effect on permeation due to the counter flux of sweep gas $[55,56]$. The concentration polarization can occur because different species in a feed mixture permeate at different rates through the membrane, which may result in accumulation of the non-preferentially permeating species and depletion of the selectively permeating species in a thin layer (boundary layer) adjacent to the membrane surface. This phenomenon changes the concentration gradient through the membrane in an unfavorable manner and deteriorates the membrane separation performance [15,52,54,57]. Thus, mathematical models which can describe the support layer, permeation of sweep gas, and concentration polarization phenomenon should also be incorporated in the design of zeolite membrane systems.

These rather complicated models should be validated by comparison with experiments and included in the process models that describe permeation through membranes at a wide range of operating conditions as encountered by membranes in industrial use.

Here, a rigorous mathematical model is developed to describe the permeation through a randomly oriented $500 \mathrm{~nm}$ thick MFI zeolite layer. The Maxwell-Stefan formulation [58], which accounts for transport through an adsorption-diffusion mechanism is used to model permeation 
through the zeolite film. The mixture adsorption is modeled using the real (non-ideal) adsorption solution theory, while the non-idealities in the diffusion process are incorporated through a phenomenon known as intersection blocking [59]. The porous support is modeled considering contributions from Knudsen and molecular diffusion, and viscous flow. The pore size, porosity, and tortuosity of the support layer are considered to be $3 \mu \mathrm{m}, 0.3$ and 2.5 , respectively. Support thicknesses of $1 \mathrm{~mm}$ and $3 \mathrm{~mm}$ are used. The sweep gas is regarded as an additional component and its permeation is modeled through both the zeolite layer and the support layer. The concentration polarization is accounted for by using a parameter known as concentration polarization index, which has been derived by solving the mass-transport equations in the boundary layer [60]. Furthermore, this detailed zeolite membrane model is incorporated into a conceptual level process model to analyze the performance of zeolite membranes in industrial settings. These models can be used to assess the commercialization potential of zeolite membranes in various industrially relevant applications. The separation of butane isomers (n-butane and 2-methylpropane or $i$-butane) using MFI-type zeolite is assessed here. The butane isomer separation is selected because the availability of both (i) molecular level transport properties and (ii) industrial scale distillation data allows for a rigorous mathematical description of membrane performance and its detailed comparison with the current industrial practice. Moreover, butanes offer a great opportunity for implementation of novel separation technologies since they are used as a fuel and as a feedstock to make plastics, and their global market is growing at an annual rate of $\sim 2.5 \%$ and is expected to reach $\sim 240$ million tons by 2018 [61].

\section{Theory}

A schematic of the membrane structure in a typical laboratory setting is shown in Figure 1a. The membrane structure consists of a zeolite layer on a porous support. The feed stream is passed across the retentate side facing the zeolite film, and the permeating species are collected by flowing a sweep gas across the permeate side. Compartments on both sides of the membrane i.e., the retentate side and the permeate side are assumed to be well-mixed. 


\subsection{Zeolite layer}

Krishna and co-workers [50,58,62-65] have extended the Maxwell-Stefan approach, which provides a fundamental description of multi-component diffusion, to formulate the generalized Maxwell-Stefan model for permeation through a zeolite membrane:

$$
-\rho \frac{\theta_{\mathrm{i}}}{R T} \nabla \mu_{\mathrm{i}}=-\rho \sum_{\mathrm{j}=1}^{\mathrm{n}} \Gamma_{\mathrm{ij}} \nabla \theta_{\mathrm{j}}=\sum_{\mathrm{j}=1, \mathrm{j} \neq \mathrm{i}}^{\mathrm{n}} \frac{q_{\mathrm{j}} N_{\mathrm{i}}-q_{\mathrm{i}} N_{\mathrm{j}}}{q_{\mathrm{i}}^{\mathrm{sat}} q_{\mathrm{j}}^{\mathrm{sat}} \bigoplus_{\mathrm{ij}}}+\frac{N_{\mathrm{i}}}{q_{\mathrm{i}}^{\mathrm{sat}} \bigoplus_{\mathrm{i}}} \quad \mathrm{i}=1,2 \ldots, \mathrm{n}
$$

where $\rho$ is the zeolite density, $\theta$ is the fractional loading, $R$ is the universal gas constant, $T$ is the absolute temperature, $\mu$ is the chemical potential, $\Gamma$ is the thermodynamic factor, $q$ is the loading, $q^{\text {sat }}$ is the saturation loading, $N$ is the flux, $\bigoplus_{\mathrm{i}}$ is the Maxwell-Stefan diffusivity and $\bigoplus_{\mathrm{ij}}$ 's are the exchange coefficients. The equation can be regarded as a force balance with the left-hand-side term representing the driving force due to a chemical potential gradient and the right-hand-side terms representing the friction forces due to molecule-molecule interactions and molecule-zeolite pore wall interactions. This formulation is used here to determine the permeation through a randomly oriented MFI zeolite layer. The structural details of MFI zeolite can be accessed from the database of zeolite structures provided by the International Zeolite Association [66]. The zeolite layer thickness is considered to be $500 \mathrm{~nm}$. The adsorption and diffusion properties for a mixture of butane isomers and the corresponding non-ideal models to predict these properties are discussed in Section 3 and 4, respectively.

\subsection{Support layer}

Permeation through the support is modeled considering contributions from Knudsen diffusion, molecular diffusion and viscous flow [53]. The pore size, porosity, and tortuosity of the support layer are considered to be $3 \mu \mathrm{m}, 0.3$ and 2.5, respectively. Support thicknesses of $1 \mathrm{~mm}$ and $3 \mathrm{~mm}$ are used. The Knudsen diffusivity $\left(D_{\mathrm{i}}^{\mathrm{k}}\right)$, which accounts for molecule-wall interactions, has been derived from the kinetic theory of gases and is given by:

$$
D_{\mathrm{i}}{ }^{\mathrm{k}}=\frac{\varepsilon}{\tau} \frac{d_{\text {pore }}}{3}\left(\frac{8 R T}{\pi M W_{\mathrm{i}}}\right)^{1 / 2}
$$


where $\varepsilon$ is the support porosity, $\tau$ is the support tortuosity, $d_{\text {pore }}$ is the support pore size and $M W$ is the molecular weight of the permeating species. The molecular diffusivity $\left(D_{\mathrm{ij}}\right)$, which accounts for molecule-molecule interactions, is estimated using the Fuller-Schettler-Giddings equation [67]:

$$
D_{\mathrm{ij}}=\frac{\varepsilon}{\tau} \frac{T^{1.75}\left(1 / M W_{\mathrm{i}}+1 / M W_{\mathrm{j}}\right)^{1 / 2}}{P\left(\left(\sum_{\mathrm{i}} v_{\mathrm{a}}\right)^{1 / 3}+\left(\sum_{\mathrm{j}} v_{\mathrm{a}}\right)^{1 / 3}\right)^{2}}
$$

where $P$ is the total pressure and $v_{\mathrm{a}}$ is the atomic volume. The partial pressure gradient due to these interactions is additive and is given by:

$$
-\frac{1}{R T} \frac{d p_{\mathrm{i}}}{d z}=\frac{N_{\mathrm{i}}}{D_{\mathrm{i}}{ }^{\mathrm{k}}}+\sum_{\mathrm{j}=1, \mathrm{j} \neq \mathrm{i}}^{\mathrm{n}} \frac{x_{\mathrm{j}} N_{\mathrm{i}}-x_{\mathrm{i}} N_{\mathrm{j}}}{D_{\mathrm{ij}}} \quad \mathrm{i}=1,2 \ldots, \mathrm{n}
$$

Apart from Knudsen and molecular diffusion, a finite total pressure gradient across the support also gives rise to viscous flux:

$$
N_{\mathrm{v}, \mathrm{i}}=-\frac{\varepsilon}{\tau} \frac{p_{\mathrm{i}}}{R T} \frac{\beta}{\mu} \frac{d P}{d z} \quad \beta=d_{\mathrm{pore}}^{2} / 32 \quad \mathrm{i}=1,2 \ldots, \mathrm{n}
$$

where $\mu$ is the mixture viscosity. The total flux is obtained by the summation of the viscous flux and the flux obtained in Eq. 4.

\subsection{Sweep gas}

The effects due to the use of sweep gas (helium is considered here) are also incorporated into the model. Since, helium has been shown to be non-adsorbing on MFI zeolites $[68,69]$ and that its density inside the zeolite is lower than that in the gas phase, its permeation through the zeolite layer is modeled using Knudsen diffusion and viscous flow. The effective pore diameter is calculated by subtracting the diameter of the helium atom from the zeolite pore size. As steady-state permeation of adsorbed species through the zeolite layer has been shown to be unaffected by non-adsorbed species [70], it is assumed that helium permeates only through the pores unoccupied by the adsorbed species. As a result, the helium flux through the zeolite layer 
is further reduced by a factor equal to fractional vacancy, given by $\left(1-\sum \theta_{\mathrm{i}}\right)$. Similar to other components, permeation of sweep gas through the support is modeled considering contributions from Knudsen and molecular diffusion, and viscous flow.

The effects of the sweep gas are twofold. While it increases the driving force by carrying away the permeating species and reducing their partial pressure on the permeate side, it also introduces a counter flux (against the permeating direction) that can have an adverse effect on permeation $[55,56]$. However, this counter flux affects the permeation only through the support layer because permeation of adsorbed species through the zeolite layer is not affected by nonadsorbing sweep gas. Thus, for a fixed total pressure on both sides (the retentate side and the permeate side) of the membrane, the use of sweep gas decreases the resistance through the zeolite layer by increasing the driving force, and increases the resistance through the support layer by introducing a counter-flux. Usually, the increase in driving force dominates the effect due to counter-flow, and membranes operated with a sweep gas result in higher flux and separation factor as compared to the membranes operated without sweep. However, this improvement by the introduction of a sweep is effective only if the transport in the membrane is governed by the zeolite layer.

\subsection{Boundary conditions}

To solve the coupled partial differential equations for the zeolite and the support layer, boundary conditions are required at the retentate side, the permeate side, and also at the zeolitesupport interface. In the absence of any external resistance (the effects of external resistance are discussed in the next section), the loading at the feed side is calculated assuming equilibrium between feed partial pressure and loading at the zeolite layer. At the zeolite-support interface, the boundary conditions are obtained by assuming that no accumulation occurs at the interface i.e. the flux of a component leaving the zeolite layer is equal to the flux entering the support layer. Equilibrium is also assumed between the loading at the zeolite layer and the partial pressure in 
the support layer at the interface. At the permeate side, the total pressure is kept constant at $1 \mathrm{~atm}$ and the mole fractions are calculated iteratively from the steady state flux of the components:

$$
x_{\mathrm{i}}=\frac{N_{\mathrm{i}}}{\sum_{\mathrm{i}} N_{\mathrm{i}}}
$$

\subsection{Concentration polarization}

The concentration polarization (Figure 1b) increases the concentration of the nonpreferentially permeating species and decreases the concentration of the selectively permeating species at the membrane surface as compared to that in the bulk feed. In most of the modeling studies, this change in concentration is neglected and the loading at the zeolite layer is assumed to be in equilibrium with the bulk feed concentration. However, it has been shown that concentration polarization can significantly affect the separation performance and appropriate models that can describe this behavior are essential [57,71]. In some studies, a simple resistancein-series model is used to describe the effects of concentration polarization, however this approach applies only to the preferentially permeating component and does not account for accumulation of non-preferentially permeating species.

As solving for the velocity and concentration profile in the boundary layer is challenging, an alternative approach based on mass transport equations is used here [60]. In this approach, the effect of concentration polarization is determined through a parameter, known as concentration polarization index, which is defined as the ratio of mole fraction of the preferentially permeating component in the bulk feed to that at the membrane surface. This index determines the severity of the concentration polarization and is strengthened with increase in membrane enrichment and/or membrane permeability, or with decrease in the external mass transfer coefficient (in the boundary layer). An expression to calculate the concentration polarization index has been derived using this approach [60] and given by;

$$
\frac{X_{\mathrm{s}}}{X_{\mathrm{f}}}=\frac{1}{\alpha-(\alpha-1) \exp (-v / k)} ; \alpha=\frac{X_{\mathrm{p}}}{X_{\mathrm{s}}}
$$


where $\alpha$ is the enrichment factor, $v$ is the molar average velocity through the membrane which represents the membrane permeability, $k$ is the external mass transfer coefficient of the more permeable component and 'f', 's' and 'p' denote the bulk feed, membrane surface and permeate, respectively. While membrane permeability and enrichment are intrinsic properties of the membranes, the mass transfer coefficient depends on the module geometry and flow conditions, and is generally represented in terms of the Sherwood number $(S h)$ [72-74].

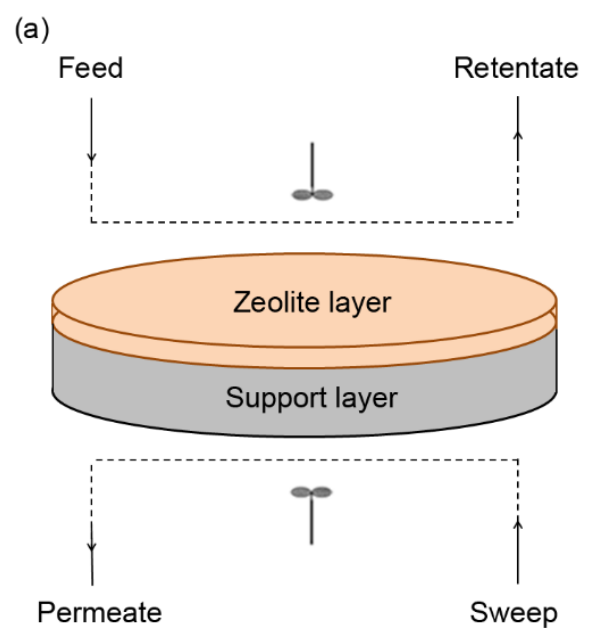

(b)

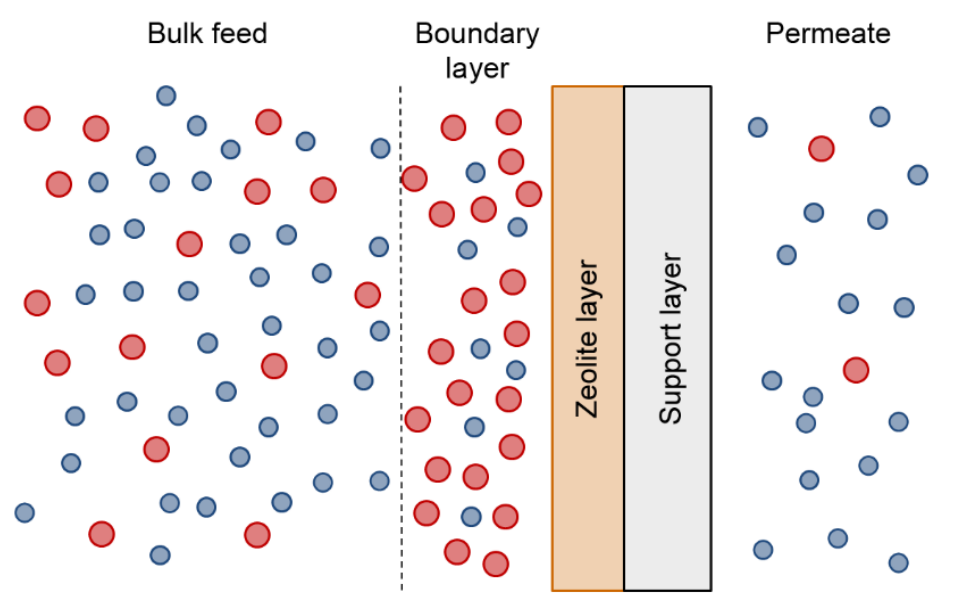

Figure 1: (a) Schematic of a zeolite membrane in a typical laboratory setting. (b) Concentration polarization leading to depletion of preferentially permeating component (,) and accumulation of less/slower permeating component (,) at the membrane surface.

\section{Adsorption parameters}

\subsection{Single component adsorption properties}

The single component adsorption properties of butane isomers in MFI zeolites have been widely studied [75-87]. Adsorption isotherms and the heats of adsorption have been determined by various experimental and molecular simulation techniques and were found to be in good agreement with one another. The adsorption has been described in terms of a volume filling process with two different types of sites - channels and intersections, and thus the dual-site Langmuir isotherm has been used to model the adsorption isotherm. $n$-Butane prefers channels over intersections for loading up to 8 molecules/UC (unit cell) and then starts filling intersections at higher pressure. On the other hand, $i$-butane (or 2-methylpropane) is preferentially adsorbed in 
the intersections for loading up to 4 molecules/UC and the channels are occupied in addition at high pressure. A detailed description of the single component adsorption properties is provided in the Supporting Information S1.1.

\subsection{Mixture adsorption properties}

Although single component adsorption of butane isomers on MFI zeolites is well established, only a few studies exist for mixture adsorption $[47,85,88,89]$. Configurational-bias Monte Carlo (CBMC) simulations [85,88] have been carried out to determine the equimolar mixture adsorption at $T=300 \mathrm{~K}$. Both isomers were shown to follow single-component behavior up to a total loading of 4 molecules/UC. For higher loadings, $n$-butane tends to squeeze-out $i$-butane molecules causing a maximum of $i$-butane loading at a total loading of 4 molecules/UC. The squeezing-out effect has been attributed to higher packing efficiency of $n$-butane versus $i$-butane molecules in the zeolite channels. For a total loading greater than 4 molecules/UC, $n$-butane loading increases with pressure while $i$-butane loading decreases with pressure. These results are also in agreement with infra-red microscopy (IRM) experiments [89]. Similar conclusions were also reached for higher temperatures by $\mathrm{Lu}$ et al. [47]. The same phenomenon has also been observed for hexane isomers ( $n$-hexane/2-methyl-pentane), i.e., linear isomer occupies both channels and intersections while the branched isomer is located preferentially at intersections $[88,90]$. At high pressure (total loading greater than 4 molecules/UC), the adsorption of the linear isomer is favored by squeezing out the branched isomer. This leads to high selectivity of the linear isomer making MFI type of zeolite an attractive choice for these isomer separations.

The squeezing-out effect also introduces non-idealities in the mixture and leads to failure of the Ideal Adsorption Solution Theory (IAST), which is widely used in predicting mixture isotherms . Though mixture rules based on Langmuir isotherm [85] and a surface area corrected IAST (SAC-IAST) model [47] have been proposed to model butane isomer mixture adsorption, these models have limitations that restrict their use to only finite operating conditions. These models and their corresponding drawbacks are further discussed in the Supporting Information 
S1.2. Thus, Real Adsorption Solution Theory (RAST), as employed by Krishna et al. [88] for alkane mixtures, is also used here to model the mixture isotherm. RAST is a more general theory than IAST and accounts for the non-idealities by incorporating activity coefficients [91]. The mathematical equations for RAST and various models for the activity coefficients are discussed in Supporting Information S1.2. The activity coefficients based on the Wilson equation are used here, and the resultant mixture adsorption isotherm at $T=300 \mathrm{~K}$ is shown in Figure 2a; the isotherms at higher temperature $(T=323 \mathrm{~K}$ and $T=343 \mathrm{~K})$ are shown in Figure S3 in the Supporting Information. The mean absolute percentage deviations of the RAST model from the simulation data are $4.96 \%$ and $3.53 \%$ for $n$-butane and $i$-butane, respectively, and $3.97 \%$ for the selectivity. Given the uncertainties of the simulation data $[47,85]$, this level of deviation is judged as acceptable for the present process modeling.

\section{Diffusion parameters}

The methods for determining micropore diffusion coefficients can be broadly classified into microscopic, macroscopic and molecular simulation methods. The diffusion of $n$-butane and $i$-butane in MFI zeolite crystals has been extensively studied in the literature using all three approaches [59,92-127]. However, the diffusion coefficients reported in the literature differ from one another by up to three orders of magnitude. Thus, the data should be carefully reviewed before selecting the diffusivity, as the permeation across the membrane is crucially dependent on these coefficients. Here, the literature data are organized and analyzed in a systematic manner (see Supporting Information S2) in an attempt to select the most appropriate values of diffusion coefficients. In order to study the propagation of the error in these parameters to the energy and economics analysis of the process, a sensitivity analysis is also carried out in the latter part of this study (see Supporting Information S7). It shows that a standard deviation of $\sim 5 \%$ from the mean values is acceptable for process modeling but an order of magnitude difference can significantly affect the energy and economic analysis. Thus, it is essential that the most reasonable values of the diffusion parameters are selected for the analysis. 


\subsection{Single component diffusion properties}

Based on the analysis presented in the Supporting Information S2, it is safe to conclude that the current macroscopic techniques are inadequate in determining the $n$-butane microporous diffusion coefficient, and the diffusivities predicted by molecular simulations are an order of magnitude higher than those obtained from the microscopic methods such as nuclear magnetic resonance (NMR) and quasi-elastic neutron scattering (QENS). Here, diffusivities obtained by NMR [93] are selected for $n$-butane based on the opinion that they closely represent the intrinsic transport in the zeolite pores. The concentration dependence is modeled using the strong confinement scenario [36], as both NMR and molecular simulation studies show a decrease in diffusivity with increase in loading. For $i$-butane, diffusivities obtained by macroscopic techniques [101] and kinetic Monte Carlo simulations [127] are found to be in good agreement with each other. Among the microscopic methods to measure $i$-butane diffusivities, which are as low as of the order of $10^{-12} \mathrm{~m}^{2} / \mathrm{s}$, values obtained by neutron spin-echo (NSE) [128] technique are considered to be more accurate than NMR and QENS [99], and are in agreement with those obtained by macroscopic measurements and kinetic Monte Carlo simulations The activation energy of $22.6 \mathrm{~kJ} / \mathrm{mol}$ from NSE [128] is also in agreement with that obtained by macroscopic techniques (of $24.5 \mathrm{~kJ} / \mathrm{mol}$ ) [101]. The pre-exponential factor of diffusion coefficient and the activation energy for both isomers selected for developing the model are shown in Table $\mathbf{1 .}$

Table 1. Pre-exponential factor of diffusion coefficient at zero loading and the corresponding activation energy for butane isomers in MFI crystals.

$\begin{array}{ccc}\text { Component } & \text { Pre-exponential factor } & \text { True activation energy } \\ n \text {-butane } & \left(10^{-8} \mathrm{~m}^{2} / \mathrm{s}\right) & (\mathrm{kJ} / \mathrm{mol}) \\ i \text {-butane } & 1.03 & 6.2 \\ & 2.19 & 24.5\end{array}$

\subsection{Mixture diffusion properties}

Generally, the corrected diffusivity of a species in a mixture is taken equal to its single component corrected diffusivity at the same total fractional loading. However, for a butane 
isomer mixture in MFI zeolite, presence of $i$-butane molecules has shown to adversely affect the $n$-butane diffusion. This effect is caused due to a phenomenon known as intersection blocking [96], which is also included in the model. It occurs when one component is preferentially adsorbed at the intersection of distinct pathways reducing the mobility of the other component. For a butane isomer mixture in MFI zeolite, $i$-butane molecules are preferentially adsorbed at the intersection of the straight and zig-zag channels, which results in reduced mobility of $n$-butane molecules [89,96]. In fact, intersection blocking is observed in MFI zeolites whenever the branched or cyclic hydrocarbons are present in the mixture along with linear (normal) hydrocarbons $[59,90]$. The branched hydrocarbon preferentially adsorbs at the intersection of MFI crystals which causes blocking of the pore and severely reduces the diffusivity of the linear alkane. However, at high pressure (total loading greater than 4 molecules/UC), the branched isomer loading decreases. Therefore, the effect of intersection blocking is diminished and transport of the linear isomer is enhanced. The synergy of adsorption and diffusion, both favoring the linear isomer, is uncommon, as most separations are based on either selective adsorption or selective membrane permeation, and is a main reason for using MFI membranes for butane-isomer and hexane-isomer separations [89,90]. Intersection blocking is further discussed in the Supporting Information S2.4.

The exchange coefficients $\left(\bigoplus_{\mathrm{ij}}\right)$ are modeled using the Vignes correlation [62]. The improved correlation in [36] also reduces to the Vignes correlation for butane isomer mixture as the saturation loadings of both isomers are the same.

\subsection{Discrepancy between diffusion properties in crystals and membranes}

In addition to the microscopic, macroscopic and molecular simulation methods employed to obtain the diffusivities in MFI crystals, single component $n$-butane corrected diffusivity has also been determined from permeation measurements through MFI membranes made up of intergrown crystals. 
Kapteijn, Mouleijn and co-workers [129-132] have carried out steady state $n$-butane permeation experiments through a $40 \mu \mathrm{m}$ thick membrane on a stainless steel support. To obtain the diffusivity from these measurements, adsorption was modeled using a single-site Langmuir isotherm and the effects of the support were incorporated using support porosity. Kapteijn et al. [129] found that the corrected diffusivity was an order of magnitude smaller than the values obtained by NMR measurements. The reported activation energy of $30 \mathrm{~kJ} / \mathrm{mol}$ is also considerably higher than the $8 \mathrm{~kJ} / \mathrm{mol}$ obtained from NMR measurements. Bakker et al. [130] later used the detailed molecular diffusion theory to model permeation through the support layer but the diffusivity values were still found to be lower. Van de Graaf et al. [131] also found similar results and concluded that the permeation through a membrane is fundamentally different than diffusion in a crystal. The higher activation energy, as compared to the values obtained using microscopic techniques, was attributed to higher energy barrier due to the randomly intergrown crystals. The reported activation energy values may also be larger because these values are determined at different finite loadings while the activation energy from NMR measurements was calculated at zero loading. After incorporating the loading dependency of diffusivity, the activation energy (at zero loading) from permeation experiments is calculated to be $9 \mathrm{~kJ} / \mathrm{mol}$, which is nearly equal to that obtained in MFI zeolite crystals using NMR measurements. Bakker et al. [132], by carrying out the permeation experiments with $i$-octane, also stated that these membranes contained non-zeolitic pores, which are larger than the zeolite pores and result in larger flux and thus overestimation of the diffusivity. Moreover, SEM images of the membranes [131] show that the crystals are loosely intergrown and thus the effective thickness of the membrane should be even less than the visual thickness of $\sim 40 \mu \mathrm{m}$. For a given flux, a higher than actual thickness also results in overestimation of the diffusivity. This implies that the actual diffusivity through the membranes could be even lower than the values obtained from the steady state permeation experiments and therefore, their differences from the values obtained by NMR could be even more pronounced. 
Burgraaf and co-workers [133-135] have studied $n$-butane permeation through $3 \mu \mathrm{m}$ thick membranes supported on $2 \mathrm{~mm}$ thick alumina support. The permeation data were analyzed using single-site Langmuir isotherm, and support porosity to account for support effects. The diffusivity values were found to be two orders of magnitude lower than those obtained by NMR measurements.

Noble, Falconer and co-workers $[37,136,137]$ have developed a method to obtain adsorption and diffusion properties by measuring permeation through the membranes. Transient permeation measurements were used to calculate adsorption parameters and membrane thickness. These parameters were further used to determine the diffusion parameters using steady state permeation measurements. A single-site Langmuir isotherm was used for the adsorption and the support was modeled using molecular diffusion. The membrane thickness was stated to be $220 \mu \mathrm{m}$ and the $n$-butane diffusion coefficients were found to be an order of magnitude lower than the values obtained by NMR measurements. The method was further extended to include a dual-site Langmuir isotherm but the resultant diffusivities did not show any considerable differences, especially at high temperature. This may be because $n$-butane isotherm can be accurately modeled using a single-site Langmuir isotherm at low pressure and high temperature. Moreover, SEM images for membranes grown with a similar technique [138] show that the continuous zeolite layer is loosely intergrown and has a thickness of $70 \mu \mathrm{m}$ with the deposited zeolite crystals extending for another $100 \mu \mathrm{m}$ into the support. Thus, the effective thickness should be < $220 \mu \mathrm{m}$ and the calculated diffusion coefficients could be an overestimation.

A comparison of the diffusivities calculated from the above discussed membrane permeation experiments, and the values obtained from NMR measurements, is shown in Figure $2 \mathbf{b}$. As the diffusivities obtained by analyzing flux through the membrane are obtained at a finite loading while the NMR values are measured at zero loading, the strong confinement scenario is used to obtain the corresponding values at zero loading for comparison. 

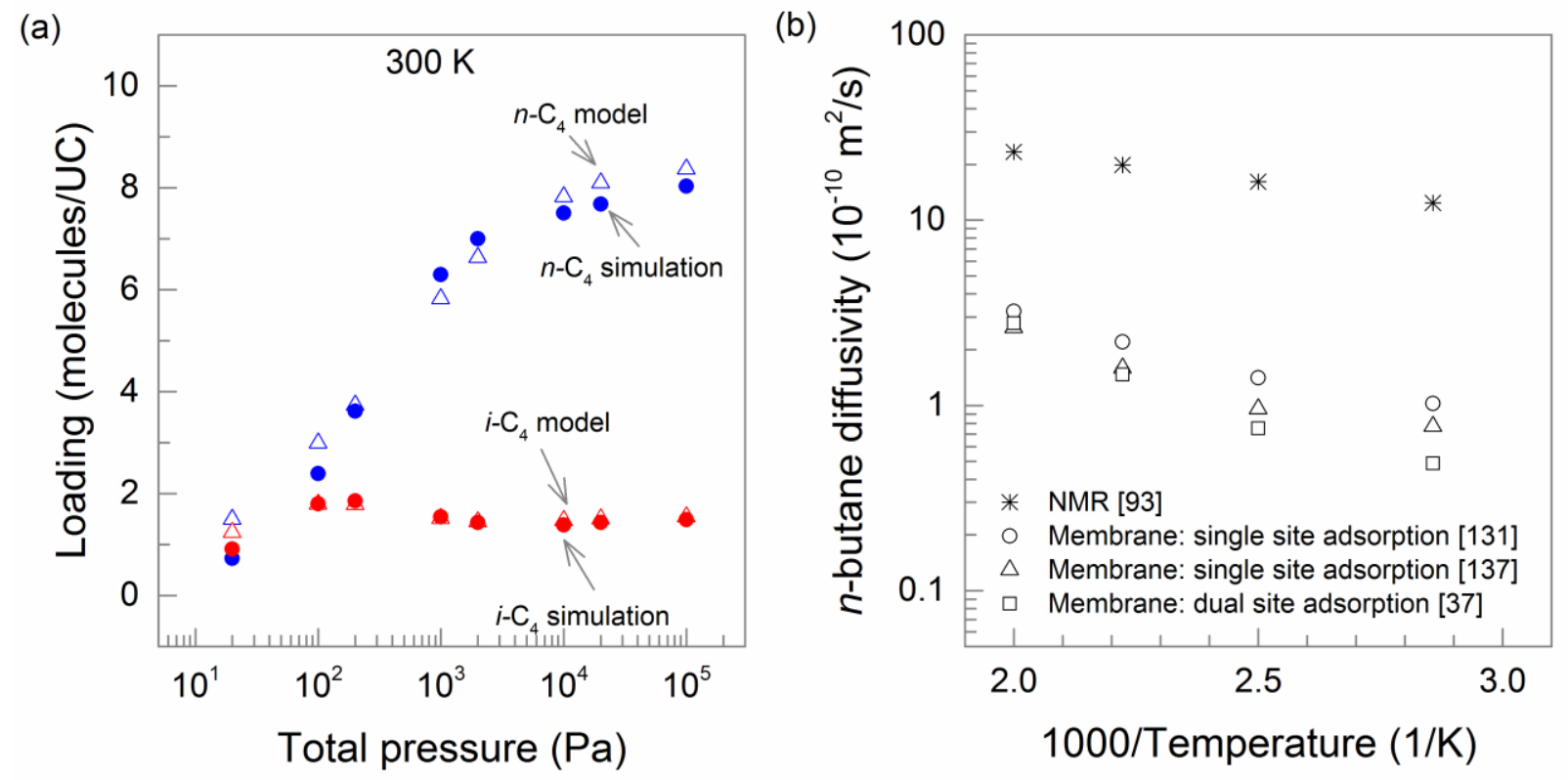

Figure 2: (a) Adsorption isotherm for an equimolar mixture of $n$-butane and $i$-butane at $T=300 \mathrm{~K}$; RAST model compared to molecular simulation data by Vlugt et al. [85].

8: $n$-butane model, , $n$-butane simulation, 8: $i$-butane model, , $i$-butane simulation

(b) Comparison of $n$-butane diffusion coefficients measured by NMR in MFI crystals to those calculated from permeation in MFI membranes. Values are corrected for finite loading and shown at zero loading.

$\square$ : NMR Heink et al. [93] -: van de Graaf et al. [131], 8: Gardner, Lee et al. [137], $\forall$ : Gardner, Falconer et al. [37].

\section{Model predictions compared to experimental results}

The real adsorption solution theory and the intersection blocking phenomenon, used to determine the butane isomer mixture adsorption and diffusion parameters respectively, were incorporated in the Maxwell-Stefan model and the resultant partial differential equations were solved in gPROMS [139]. Models for the support layer, sweep gas and concentration polarization were included. The results were obtained for $500 \mathrm{~nm}$ thickness zeolite layer and 3 mm thickness support (pore size: $3 \mu \mathrm{m}$, porosity: 0.3 , and tortuosity: 2.5 ) by simulating an equimolar feed at total pressure of $1 \mathrm{~atm}$ and the permeate side, also set at $1 \mathrm{~atm}$, with Helium as the sweep gas. The steady-state flux and separation factors predicted by the model are also compared to those determined by experiments [23] performed under the same conditions, and shown in Figure 3a and 3b, respectively. Simulation results for zeolite membrane "without support" i.e. neglecting the effect of the support are also shown. The computed separation factors 
for the membrane (including the zeolite layer and the support) are almost 5-fold lower than the ones calculated for zeolite membrane "without support", which suggests that the butane permeation in the model is mostly governed by the (non-selective) transport through the support layer. Significantly lower values of flux for the membrane, as compared to those for zeolite membrane "without support" also suggest the same. On the other hand, the experimental values for the separation factor are nearly equal to the values obtained for the simulated case of zeolite membrane "without support". Assuming that the simulation prediction for the intrinsic separation factor is correct, this suggests that the permeation in the experiments is mostly governed by the zeolite layer.

The comparison between the experimental and the simulated values indicates that the permeation rate in the real membranes is lower than that predicted by modeling based on the NMR transport data. This discrepancy has also been mentioned in the literature [37,129-137], as discussed in section 4.3. To account for this discrepancy, the corrected diffusivity values for both isomers in the model are decreased, and a reduction by a factor of $50\left(\bigoplus=\bigoplus_{0} / 50\right)$ gives values in good agreement with the experiments (Figure 3a-b). The agreement is further improved when the effects of concentration polarization are also included. 

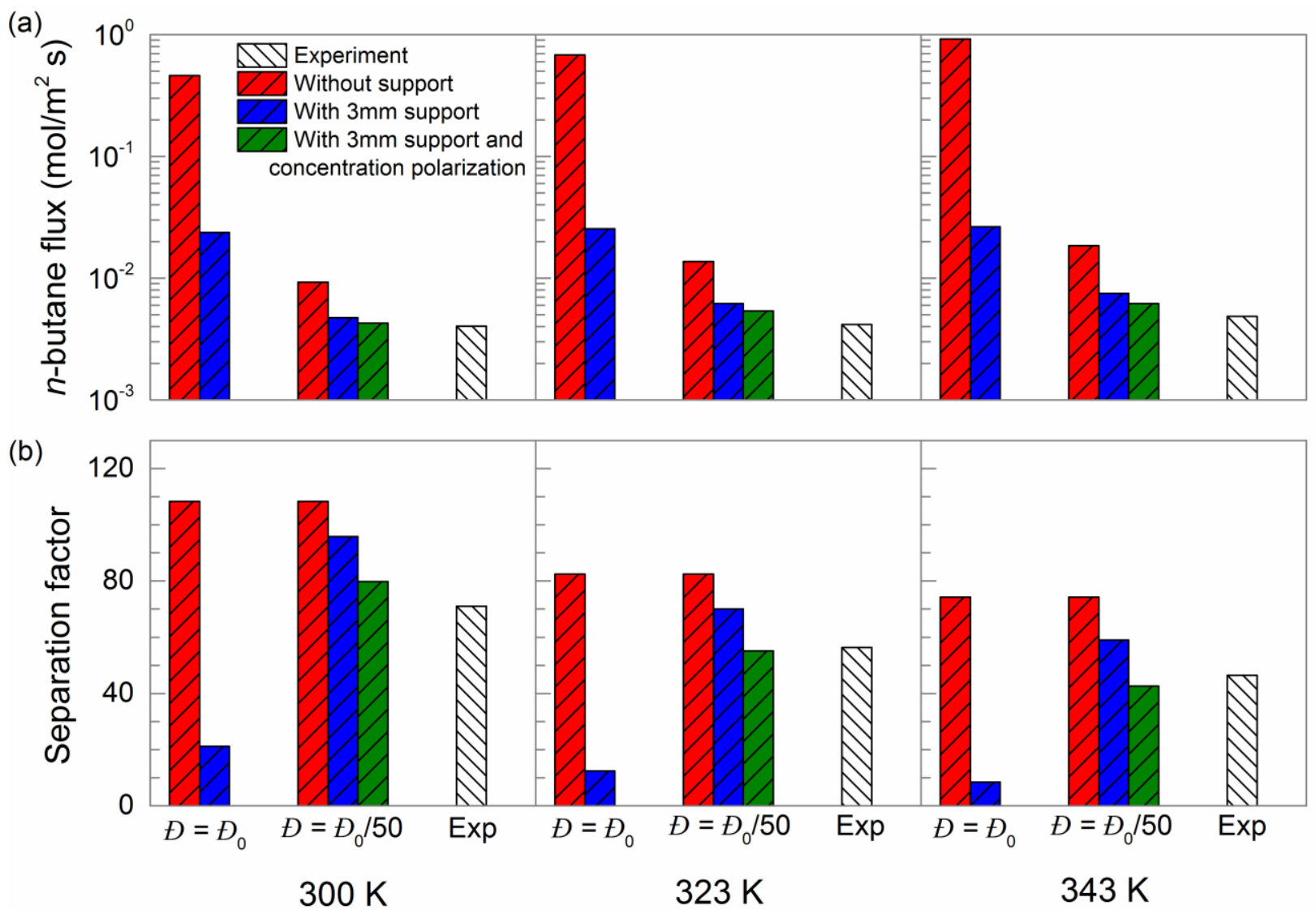

Figure 3: Model predictions compared to experimental values (Agrawal et al. [23]) of (a) $n$-butane flux (b) separation factor.

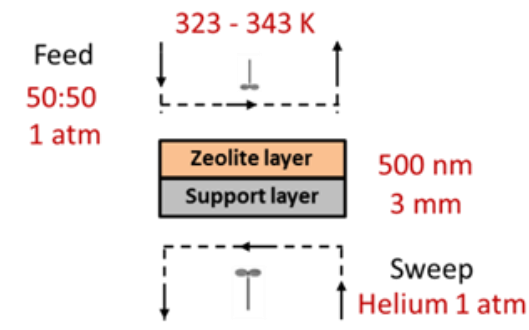

A possible reason for the reduced mobility may be the more rigid structure of zeolite membranes as compared to free standing zeolite crystals which can be more flexible. When the size of the permeating molecule is similar to or slightly larger than the pore size of the crystal, the molecule could still permeate through the pores by expansion of the crystal. However, zeolite membranes grown over a rigid support do not allow the expansion of the membrane pores, and thus the permeation through the rigid membrane is decreased. Jeong et al. [140] have shown that the MFI crystals during the membrane synthesis are under compressive stress and thus differ 
from the crystals in MFI powder. They have shown that the crystals in c-oriented membranes are contracted along the a-axis and b-axis (in-plane) and elongated along the c-axis (out-of-plane). Rangnekar et al. [141] have also observed a similar phenomenon with nanosheets. Although other explanations, like pore blockage for a large fraction of the membrane pores could also be responsible for this discrepancy, a reduction in the value of the diffusion coefficients used in the model is adapted here as a reasonable approach. In what follows, the model is further used to analyze the scope of improvement and a process level model is developed and simulated to determine the economic feasibility of membrane separation processes for butane isomer mixtures.

\section{Scope of improvement}

As the diffusivity of butane isomers in the current real (experimentally available) MFI membranes is predicted to be 50-fold lower than the diffusivity values realized in free-standing MFI crystals, there is a considerable scope of improvement in the separation of butane isomers using MFI membranes. Three different cases for improvement in the current values of diffusion coefficients in membranes are analyzed - improvement by a factor of $5\left(\bigoplus=\bigoplus_{0} / 10\right)$, $10\left(\bigoplus=\bigoplus_{0} / 5\right)$ and $50\left(\bigoplus=\bigoplus_{0}\right)$; where $\bigoplus_{0}$ refers to the diffusion coefficient in free-standing MFI crystals, which is the largest theoretically achievable value. This 5 to 50 -fold improvement could be realized by improving the membrane microstructure to reduce strain in zeolite films and increase the diffusivity in the membrane by up to 50 -fold. In practice, the flux increase could be equivalently achieved, by further decreasing the membrane thickness. If pore blocking is responsible for the discrepancy, then its elimination or the corresponding membrane thickness reduction will be required to improve flux.

As the permeance across the membrane increases, the relative contribution of the resistances due to support layer, sweep gas and concentration polarization increases. Thus, the effect of these factors on the membranes with improved diffusion is analyzed next in order to determine: (i) if and when a thinner support is desirable, (ii) under what conditions one should use the sweep 
gas, and (iii) to what extent the permeation through zeolite layer can be improved so that the concentration polarization does not become a limiting factor.

\subsection{Effect of support and sweep gas on membranes with improved performance}

Improved permeation through the zeolite layer will increase the relative support resistance which can lead to lower separation factors. Thus, simulations were also carried out with a thinner support layer of $1 \mathrm{~mm}$ thickness, which should be still strong enough to hold the zeolite layer. The separation performance of improved membranes for various temperatures and feed pressures is shown in the Supporting Information S3, and suggests that sub-mm support is essential for membranes with improved performance.

As the relative support layer resistance for membranes operated without any sweep is less compared to membranes operated with a sweep, membrane permeation without sweep gas was also studied. The separation performance of improved membranes for various feed pressures is shown in the Supporting Information S4, and suggests when operated without sweep, even a $3 \mathrm{~mm}$ thick support can be used to obtain the same separation factor as obtained with a zeolite membrane "without support".

As the absence of sweep gas has an adverse effect on separation performance, $n$-butane flux and separation factors obtained for membranes operated with sweep and without sweep for a fixed support thickness of $3 \mathrm{~mm}$ are compared in Figure 4a-b. The results indicate that, especially at higher pressure, there is only a marginal increase in the values when the sweep is introduced. Moreover, if the sweep gas is used, subsequent purification steps are required to separate $n$-butane from sweep gas itself. Thus, for process design studies, support thickness of $3 \mathrm{~mm}$ is used and membrane operation is considered without sweep. 

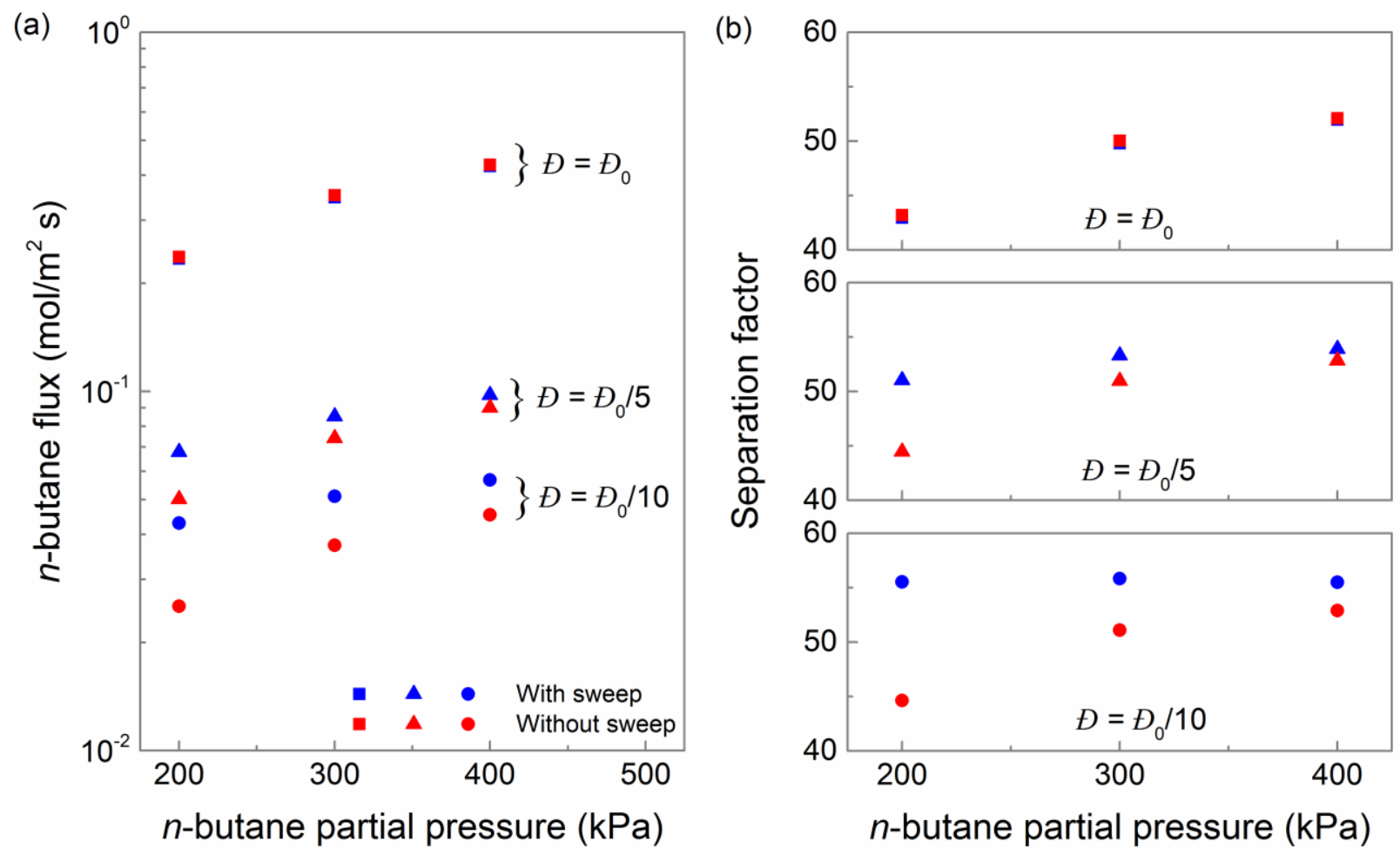

Figure 4: Effect of sweep gas on permeation through membranes with improved performance. Values are shown for a 5-fold $(D=$

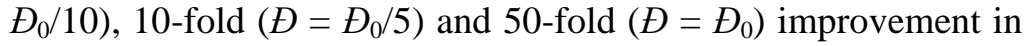
diffusivity compared to the value used to model experimentally observed permeance $\left(\nexists=\emptyset_{0} / 50\right)$ where $\bigoplus_{0}$ is the diffusivity predicted by theory. (a) $n$-butane flux (b) separation factor.

Feed: equimolar $n$-butane/ $i$-butane mixture at a $T=343 \mathrm{~K}$. Sweep (when present): Helium at $1 \mathrm{~atm}$. Membrane thickness: $500 \mathrm{~nm}$.

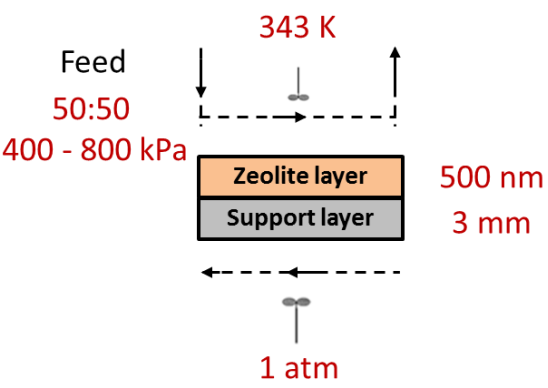
Support thickness: $3 \mathrm{~mm}$.

\subsection{Effect of concentration polarization on membranes with improved performance}

The improved membrane permeability will also enhance the contribution from concentration polarization. As stated earlier, concentration polarization depends on the membrane permeability, membrane enrichment and the external mass transfer coefficient. The membrane permeability and enrichment are determined by solving the transport equations (Maxwell-Stefan model) through the membrane. The mass transfer coefficient is directly proportional to the Sherwood number and inversely proportional to the characteristic thickness of the boundary layer. While the Sherwood number depends on the module geometry and flow conditions, the characteristic thickness depends only on the geometry. The three most common geometries are 
selected here: circular tube, annulus and tube bundles (Figure 5). For all three geometries, the characteristic thickness is equal to the hydraulic diameter, and the Sherwood number for laminar and turbulent flow regime is obtained from the literature [72-74]. A discussion on the values of the Sherwood number for the above mentioned geometries is provided in the Supporting Information S5. The Sherwood numbers for annulus and tube bundles are nearly equal.

(a)

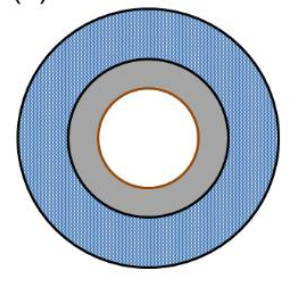

Membrane

Feed/Retentate side

Permeate side (b)

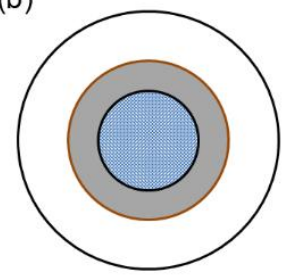

(c)

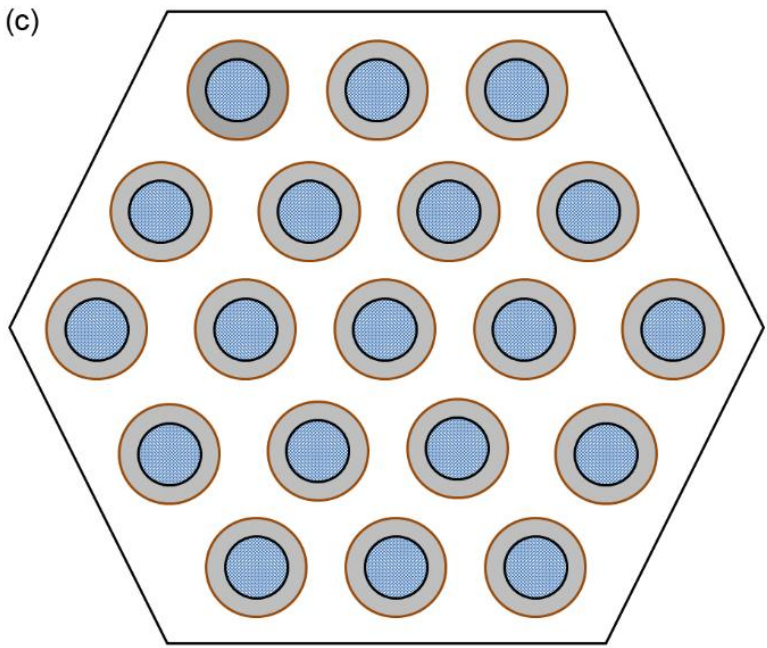

Figure 5: Cross-section of various geometries (a) flow in a circular tube (b) flow in a concentric annulus, and (c) flow on the outer surface of tube bundles.

The effect of concentration polarization on the separation performance of membranes with improved performance is shown in Figure 6a-b. While the $n$-butane flux and separation factors for a 5-fold $\left(Ð=\bigoplus_{0} / 10\right)$ and a 10-fold $\left(Ð=\bigoplus_{0} / 5\right)$ improvement in diffusivity from the currently achieved performance experimentally $\left(Ð=\bigoplus_{0} / 50\right)$ are less affected, the corresponding values for a 50-fold $\left(\bigoplus=\bigoplus_{0}\right)$ improvement in diffusivity are significantly lower when concentration polarization is taken into account. Thus, a 10-fold improvement in the diffusivity (with respect to the diffusivity that fits the currently available experimental data) is a reasonable upper limit. Even if one achieves a higher permeation by either improving transport (increasing diffusivity) in the zeolite layer or, equivalently, by reducing membrane thickness, external resistances will start to dominate and the performance will deteriorate accordingly. 


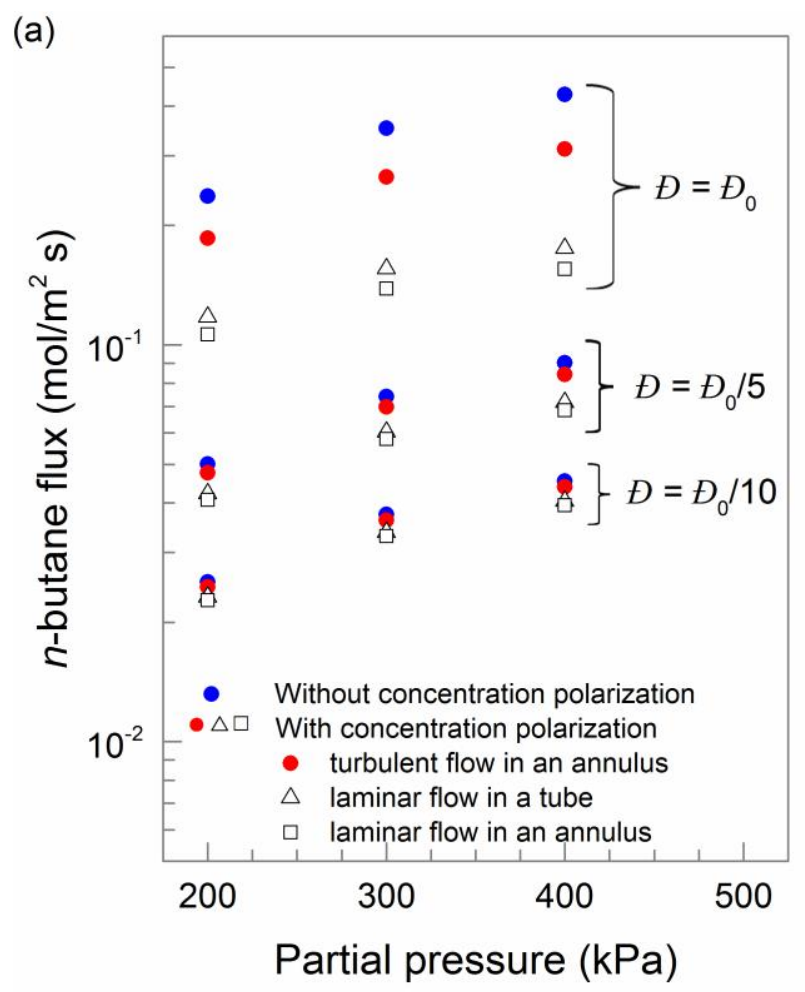

Figure 6: Effect of concentration polarization on permeation through membranes with improved performance. Values are shown for a 5-fold $\left(Ð=\bigoplus_{0} / 10\right), 10$-fold $\left(Ð=\bigoplus_{0} / 5\right)$ and 50-fold $\left(\nexists=\bigoplus_{0}\right.$ ) improvement in diffusivity compared to the value used to model experimentally observed permeance $\left(Ð=\bigoplus_{0} / 50\right)$ where $\bigoplus_{0}$ is the diffusivity predicted by theory. (a) $n$-butane flux (b) separation factor.

Feed: equimolar $n$-butane/i-butane mixture at a $T=343 \mathrm{~K}$. Membrane thickness: $500 \mathrm{~nm}$. Support thickness: $3 \mathrm{~mm}$.
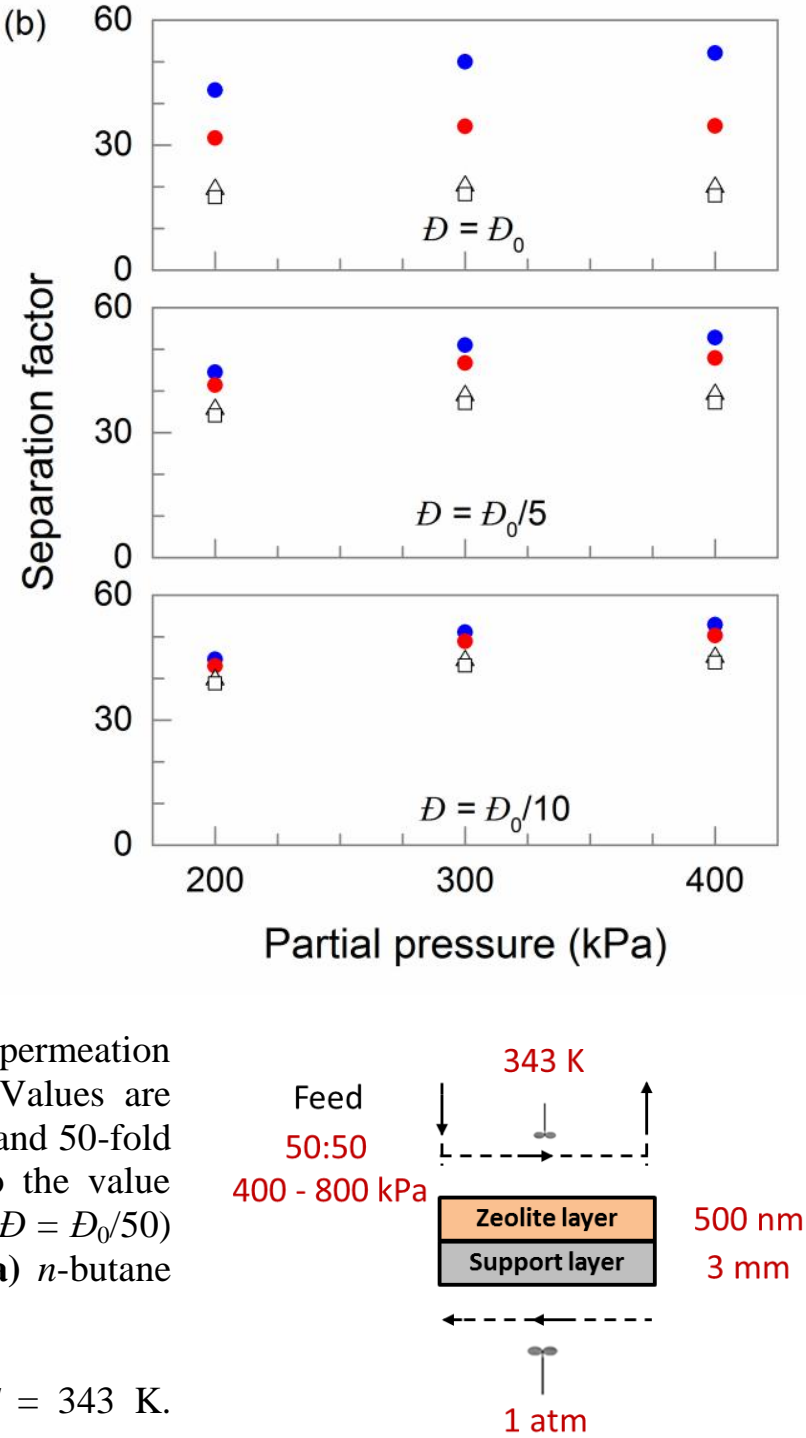

\section{Process design}

In the model developed to describe the experimental results obtained in the laboratory, the retentate and the permeate compartments are assumed to be well-mixed. Such designs assume that the operating conditions such as temperature, pressure, and composition do not change along the module length, resulting in fixed permeance and selectivity. However, simulation of an industrial membrane process requires the use of models that account for changes in operating conditions along the membrane length. Here, the governing equations for studying the effects of operating conditions were combined with the Maxwell-Stefan model to assess the industrial 
potential of zeolite membranes. A tubular membrane design (single tube cartridge or tubes packed together in small bundle) is considered, and a schematic of a single circular tube with feed on the shell side is shown in Figure 7a. The feed can flow on either side, depending upon the position of the zeolite layer. As suggested earlier, a $3 \mathrm{~mm}$ thick support membrane is simulated without any sweep and the concentration polarization effects are assumed to be negligible as diffusivity values for only up to a 10-fold improvement $\left(\bigoplus=\bigoplus_{0} / 5\right)$ are considered.

A plug flow model is used on the retentate and the permeate sides. The governing mass balance equations for each component are as follows:

$$
-\frac{d F_{\mathrm{i}}}{d x}= \pm 2 \pi r N J_{\mathrm{i}}
$$

where the +ve sign refers to the retentate side while the -sign refers to the permeate side, $F$ is the flow rate along the membrane, $J$ is the flux through the membrane, $r$ is the external radius of the tube and $N$ is the total number of tubes in a bundle. As it may be difficult to maintain turbulence in sub-cm radius tubes, only laminar flow is considered, and the pressure drop on the retentate side along the membrane length is modeled using the Hagen-Poiseuille equation:

$$
-\frac{d P}{d x}=\frac{8 \mu \rho F}{\pi r^{4} N}
$$

where $P$ refers to the total pressure [74]. The physical properties, i.e. mixture density $(\rho)$, and viscosity $(\mu)$ are obtained using Soave-Redlich-Kwong (SRK) method [142] and SuperTRAPP method [143], respectively, and are incorporated into gPROMS as a Multiflash file by using the physical properties foreign object tool. The permeate side is operated at $1 \mathrm{~atm}$, unless specified. The flux through the membrane is obtained using the detailed Maxwell-Stefan model developed in the previous sections. Accordingly, the partial pressure $(p)$ on both the retentate and the permeate side across the membrane are obtained as follows:

$$
p_{\mathrm{i}}=\frac{F_{\mathrm{i}}}{\sum_{\mathrm{j}} F_{\mathrm{j}}} P
$$


This complete model, i.e., the flow model along the membrane length combined with the Maxwell-Stefan model for membrane transport is solved using gPROMS [139]. Both the standalone membrane processes and the hybrid membrane/distillation processes are considered to analyze the industrial feasibility of MFI membranes for butane isomer separation. To evaluate the benefits of using these membrane-based designs, a distillation technology was selected as the base case, and is discussed next.

\subsection{Base Case}

Industrial separation of butane isomers is currently accomplished using distillation. The feed conditions and the separation performance obtained from the literature [144] are summarized in Table 2. A distillation column for the same performance was also simulated in Aspen Plus [145]. The reboiler and condenser duty of the simulated model are almost the same as those of the industrial column but the number of trays in the simulated model was found to be 90 as opposed to 74 trays in the industrial column. A similar discrepancy has also been reported earlier [144], and thus an overall column efficiency of $122 \%$ was used to simulate the industrial performance.

The column size data and the reboiler and condenser duties were used to estimate the capital and the annual operating costs of the column, respectively, and are shown in Table 3 [146,147]. Although the reboiler duty and the condenser duty are of the same magnitude, the reboiler makes up for the majority of the operating costs due to the requirement of expensive steam as compared to low cost cooling water required for the condenser.

Table 2. Feed conditions and separation performance of distillation for butane isomer separation

\begin{tabular}{ll}
\hline Pressure & $8.81 \mathrm{~atm}$ \\
Temperature & $343 \mathrm{~K}$ \\
Flowrate & $121.8 \mathrm{~mol} / \mathrm{s}$ \\
$n$-butane wt \% & $69.6 \%$ \\
\hline Recovery & $98.8 \%$ \\
Purity & $99.7 \%$ \\
\hline
\end{tabular}


Table 3. Capital and annual operating cost of distillation column for butane isomer separation

\begin{tabular}{ll}
\hline Column height & $51.8 \mathrm{~m}$ \\
Column diameter & $2.9 \mathrm{~m}$ \\
Total number of trays & 74 \\
Feed tray location & 37 \\
\hline Capital Cost (CAPEX) & $2.59 \mathrm{MM} \$$ \\
\hline & \\
Cooling duty & $11.09 \mathrm{MW}$ \\
Heating duty & $10.72 \mathrm{MW}$ \\
\hline Operating Cost (OPEX) & $2.25 \mathrm{MM} \$$ \\
\hline Total Cost $(\mathbf{O P E X}+\mathbf{C A P E X )}$ & $\mathbf{4 . 8 4} \mathbf{M M \$}$ \\
\hline MM $\left.\$=10^{6} \$\right)$ &
\end{tabular}

The feed location of the distillation column was also optimized to minimize the reboiler duty for the same separation performance and same number of trays. The reboiler duty and the condenser duty for the optimized base case is found to be $1.13 \mathrm{MW}$ and $1.14 \mathrm{MW}$ lower respectively. This reduces the operational cost from 2.25 MM\$/year to 2.01 MM\$/year.

\subsection{Single stage membrane process}

A single-stage membrane unit (Figure $\mathbf{7 b}$ ) is investigated initially as an alternative to distillation. For a target recovery of $98.8 \%$, the purity is found to be $97 \%$ which is less than the target value of $99.7 \%$. Membrane operation with lower pressures on the permeate side (pervaporation) was also examined. As discussed in the Supporting Information S6, pressures below $10 \mathrm{kPa}$ do not appear practical for industrial implementation of butane isomer separation due to excessive cooling requirements. Simulations performed with a total permeate pressure of $10 \mathrm{kPa}$ suggest that purity increases only marginally to $97.6 \%$, which is still below the required target of $99.7 \%$. Thus, a multi-stage membrane unit is required to improve the product purity.

\subsection{Multistage membrane process}

A schematic of the two-stage membrane unit considered is shown in Figure 7c; the design consists of two membrane stages operated in series with permeate from the first stage being fed to the second stage. An inter-stage compressor is also used to increase the pressure of the feed to the second stage. The total recovery is the product of the recovery of the two stages. Since the 
feed to the second stage is more enriched in $n$-butane as compared to the feed to the first stage, the driving force for $n$-butane permeation is greater in the second stage. Thus, a higher recovery is selected for the second stage i.e. $99.8 \%$ which sets a first stage recovery of $99 \%$ in order to achieve the target total recovery of $98.8 \%$. The area required for the current membranes $\left(\bigoplus=\bigoplus_{0} / 50\right)$ and product purity obtained for different compressor discharge pressure are shown in Table 4.

Table 4. Membrane area and product purity for two-stage membrane system

\begin{tabular}{llllll}
\hline $\begin{array}{l}\text { Compressor } \\
\text { Output }\end{array}$ & $\begin{array}{l}\text { Stage \#1 } \\
\text { Area }\left(\mathbf{m}^{\mathbf{2}}\right)\end{array}$ & $\begin{array}{l}\text { Stage \#1 } \\
\text { Purity } \mathbf{( \% )}\end{array}$ & $\begin{array}{l}\text { Stage \#2 } \\
\text { Area }\left(\mathbf{m}^{\mathbf{2}}\right)\end{array}$ & $\begin{array}{l}\text { Stage \#2 } \\
\text { Purity } \mathbf{( \% )}\end{array}$ & $\begin{array}{l}\text { Total } \\
\text { Area }\left(\mathbf{m}^{\mathbf{2}}\right)\end{array}$ \\
\hline $2 \mathrm{~atm}$ & 16,697 & 96.89 & 25,070 & 99.34 & 41,767 \\
$5 \mathrm{~atm}$ & 16,697 & 96.89 & 10,970 & 99.59 & 27,667 \\
$8 \mathrm{~atm}$ & 16,697 & 96.89 & 8,812 & 99.57 & 25,509 \\
\hline
\end{tabular}

There are only marginal savings in membrane area for compressor discharge pressure over $5 \mathrm{~atm}$. This is because the adsorption isotherm reaches saturation and increasing pressure further does not improve the flux through the membrane. The results also show that a significantly large membrane area is required to match the performance of the distillation unit. Even for a 10-fold improvement in diffusivity $\left(\bigoplus=\bigoplus_{0} / 5\right)$, the area required is found to be $\sim 3,000 \mathrm{~m}^{2}$. In comparison, the largest zeolite membrane facility (implemented for $i$-propanol dehydration at Jiangsu Chemical Co. Ltd in 2012 by Dalian Institute of Chemical Physics) utilizes an area of only $350 \mathrm{~m}^{2}[13]$.

The area requirement can be reduced by lowering the pressure on the permeate side. Simulations foe a total permeate pressure of $10 \mathrm{kPa}$ suggest a 3 -fold decrease (from $\sim 3,000 \mathrm{~m}^{2}$ to $\sim 1,000 \mathrm{~m}^{2}$ ) in the required membrane area. However, the profits gained form the reduced area should be considered in conjunction with the increased costs associated with the use of vacuum. A preliminary analysis suggests that pervaporation is beneficial only if the membrane cost is more than $\$ 3,000 / \mathrm{m}^{2}$. 


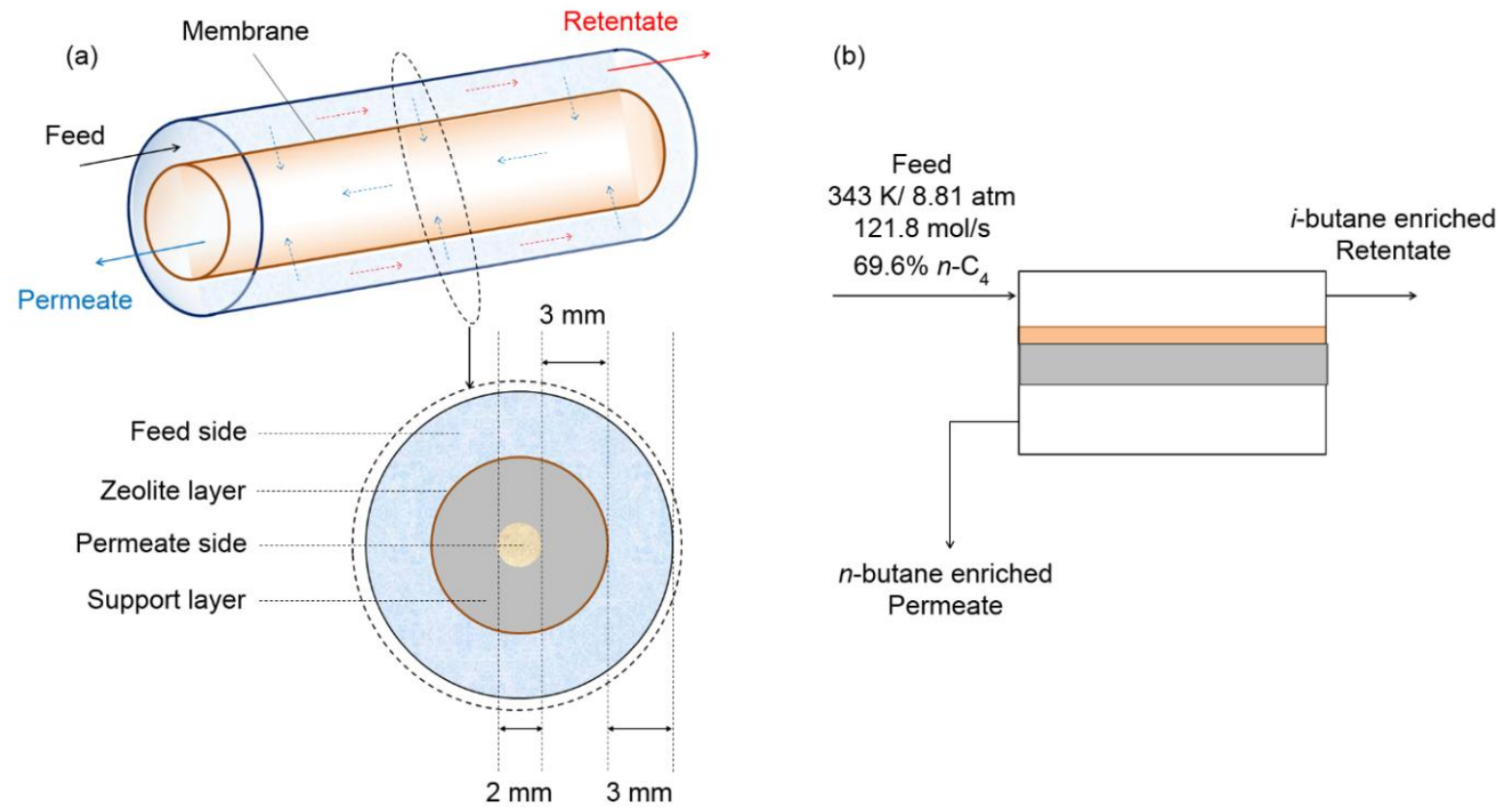

(c)

(d)

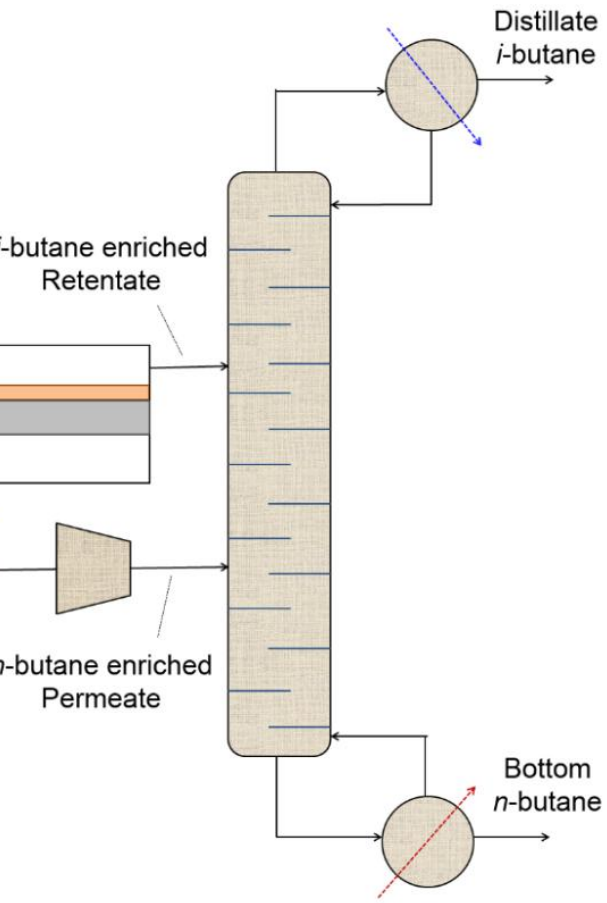

Figure 7: Schematic of (a) a tubular membrane, (b) a single stage membrane unit, (c) a two stage membrane unit, and (d) a series hybrid membrane distillation unit for butane isomer separation.

Additionally, complete replacement of the columns in operation will be not only technically challenging, but also economically unfavorable because of the long life of the existing depreciated capital infrastructure. For these reasons, a hybrid membrane/distillation process is examined next. 


\subsection{Hybrid membrane/distillation process}

As a stand-alone distillation process is energy intensive while a stand-alone membrane separation process requires prohibitively large area (at current availability levels), a hybrid membrane/distillation process, which exploits the advantages of both processes while minimizing the negative aspects, might be a feasible alternative. Various studies have shown that the hybrid membrane/distillation process is energy efficient and economically beneficial for mixtures which are otherwise impossible or difficult to separate using conventional distillation [149-152]. Such mixtures are characterized by either formation of an azeotrope (ethanol-water), or the presence of tangent pitch (water-acetic acid), or low relative volatilities (olefin-paraffin) [152]. The most common hybrid configurations containing a single distillation column and a single membrane process are shown in the Figure S15 in the Supporting Information [151,152].

In the top hybrid (Figure S15a) and bottom hybrid (Figure S15b) configurations, distillation is used as a pretreatment step while the final separation is carried out by membrane separation. Such configurations are better suited for mixtures having a tangent pitch or forming an azeotrope. Moreover, the membrane should have a high separation factor to achieve the purity target. In series hybrid (Figure S15c) and parallel hybrid (Figure S15d) configurations, membrane separation is used as a pretreatment step followed by distillation to achieve the final product specifications. They are generally used for mixtures with low relative volatility and/or when membranes cannot provide high purity separations. Thus, series and parallel configurations are more suitable for butane isomer separation. In a series configuration, the feed composition to the membrane unit is fixed, while in a parallel configuration it can be varied depending upon the stage of side stream extraction from the distillation column. However, it has been shown that the side draw stage in a parallel configuration is usually located near the feed stage where the distillation is least effective [149,153-156], which effectively makes it similar to the series configuration. Sometimes, a vapor feed is preferred over a liquid feed for the membrane 
separation to eliminate the heavy impurities which otherwise may clog the membrane pores. In those cases, if the original feed is liquid then a parallel configuration with a vapor side draw can be used. Here, only the series configuration (Figure 7d) is considered which is also expected to be easier to retrofit and control as compared to the parallel configuration.

As the governing equations for the membrane unit and the distillation unit can be solved sequentially in a series configuration, the membrane unit was simulated in gPROMS while the distillation unit was simulated in Aspen Plus. The permeate stream from the membrane was compressed to match the column pressure; a multistage compressor with inter-stage cooling was implemented to achieve the required pressure of $7 \mathrm{~atm}$. The location of the two feed streams to the distillation column (retentate and permeate streams from the membrane unit) was optimized for a fixed membrane stage-cut $(\varphi)$ to minimize the reboiler duty. The membrane stage cut $(\varphi)$ is defined as the ratio of $n$-butane flow rate in the permeate stream to that in the feed.
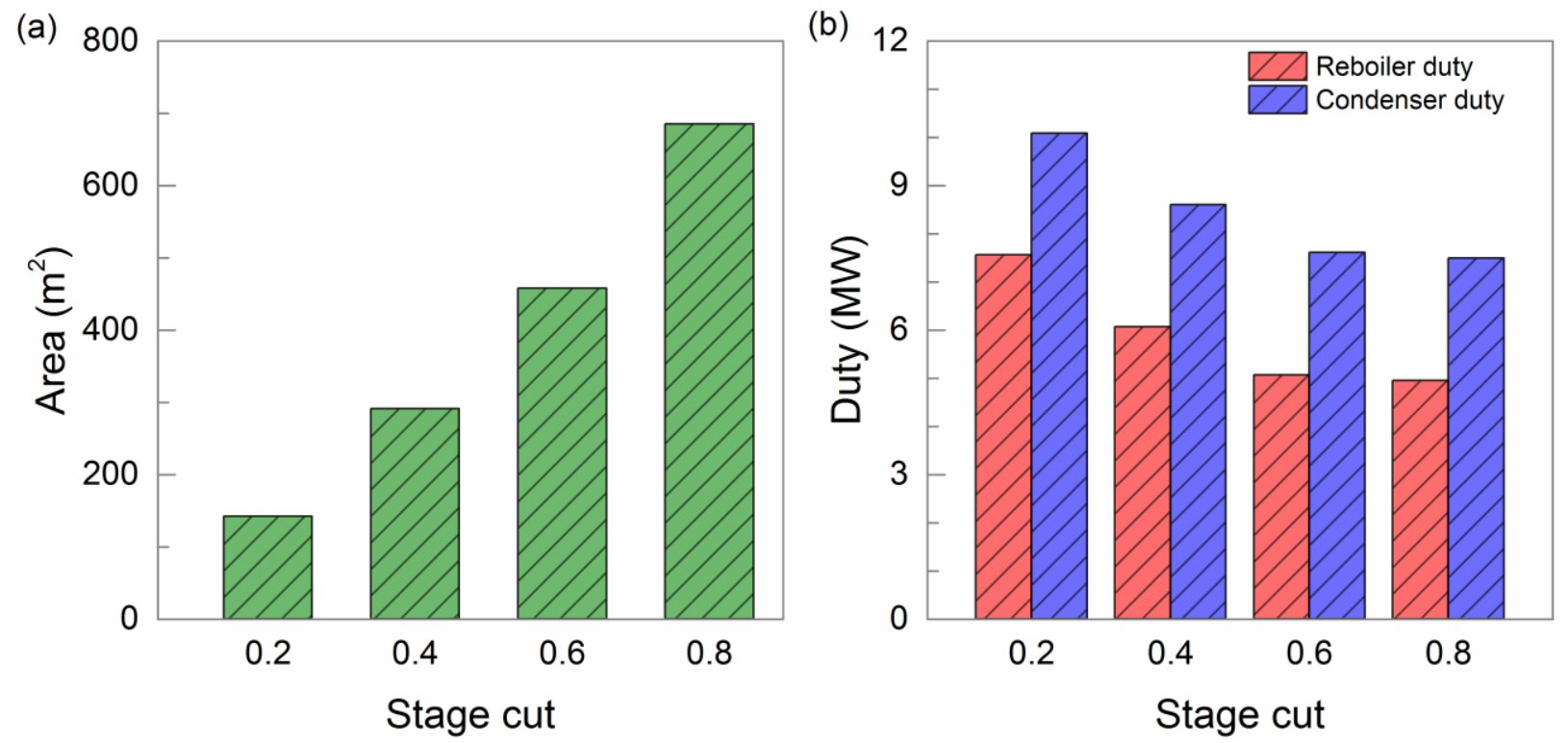

Figure 8: (a) The membrane area required for a hybrid membrane distillation unit calculated with a 10fold improvement in diffusivity $\left(\bigoplus=\Xi_{0} / 5\right)$ compared to the value used to model experimentally observed permeance $\left(\nexists=\bigoplus_{0} / 50\right)$ where $\bigoplus_{0}$ is the diffusivity predicted by theory. For reference, the area required for a two-stage membrane unit is $\sim 2,500 \mathrm{~m}^{2}$. (b) The corresponding reboiler and condenser duties for the hybrid membrane distillation unit. For reference, the reference reboiler and condensed duty for current distillation technique is $10.72 \mathrm{MW}$ and $11.09 \mathrm{MW}$ respectively. 
The membrane area and the reboiler and condenser duties required for various values of $\varphi$ are shown in Figure 8a and 8b, respectively. A membrane with a 10-fold improvement in permeation $\left(Ð=\bigoplus_{0} / 5\right)$ compared to the value used to model experimentally observed permeance $\left(\bigoplus=\bigoplus_{0} / 50\right)$, where $\bigoplus_{0}$ is the diffusivity predicted by theory, was used to calculate the required area. For $\varphi=0.4$, the reboiler duty is almost half of the stand-alone distillation column and the membrane area $\left(\sim 300 \mathrm{~m}^{2}\right)$ is almost one-tenth of the stand-alone membrane process, and is comparable to that used in the existing zeolite membranes in industry $\left(\sim 350 \mathrm{~m}^{2}\right)$. An NPV (net present value) analysis was also carried out to determine NPV savings projections over base-case distillation. A discount rate of $7 \%$ per annum was assumed. Furthermore, the membrane was assumed to have a lifetime of 5 years and to cost $50 \%$ of the initial investment when replaced. The capital and operating expenses for the additional heat exchangers and compressors were also included in the analysis. The NPV savings calculated with 10-fold improved permeation membranes $\left(Ð=\bigoplus_{0} / 5\right)$ for different values of $\varphi(0.2-0.8)$ at a fixed membrane cost of $\$ 1000 / \mathrm{m}^{2}$, and for membrane cost in the range of $\$ 1000 / \mathrm{m}^{2}-\$ 5000 / \mathrm{m}^{2}$, which is a rough estimate of cost of a zeolite membrane [5], at a fixed $\varphi=0.4$ are shown in Figure 9a and 9b, respectively. For $\varphi=0.4$, a payback period of $\sim 3$ years can be achieved with installed membrane cost of up to $\$ 5,000 / \mathrm{m}^{2}$. Simulations were also performed for pervaporation with a total permeate pressure of $10 \mathrm{kPa}$. A preliminary analysis suggests that for a similar payback period, pervaporation is beneficial only if the membrane cost is more than $\$ 5,000 / \mathrm{m}^{2}$.

The hybrid case was also analyzed for the current membrane performance. For $\varphi=0.4$, the required membrane area is calculated to be $\sim 3,000 \mathrm{~m}^{2}$, which is 10 -fold than the corresponding area required for the improved permeation membranes. This large area requirement brings down the NPV savings, and membrane cost as low as $\$ 500 / \mathrm{m}^{2}$ is needed to achieve a payback period of $<3$ years. To reduce the area requirement, a preliminary analysis was also carried out with a pervaporation system (permeate pressure of $10 \mathrm{kPa}$ ). Although, pervaporation leads to a $\sim 3$ fold 
decrease (from $\sim 3,000 \mathrm{~m}^{2}$ to $\sim 1,000 \mathrm{~m}^{2}$ ) in the required membrane area, it was found to be profitable only if the membrane cost is more than $\$ 500 / \mathrm{m}^{2}$.
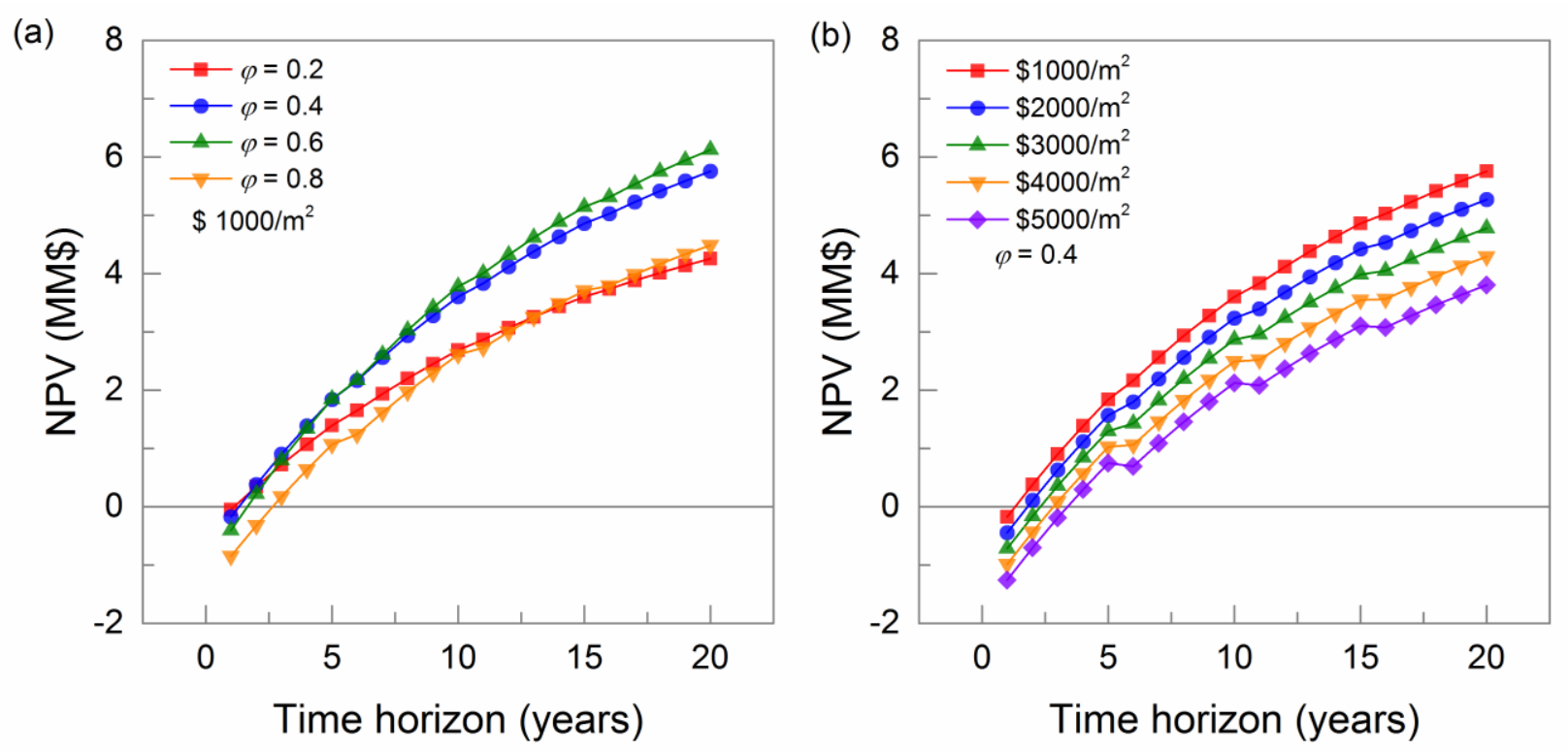

Figure 9: NPV savings projection of a series hybrid membrane-distillation system over current distillation technique for a fixed (a) membrane cost $=\$ 5000 / \mathrm{m}^{2}$, and (b) stage cut $(\varphi)=0.4$, calculated with a 10-fold improvement in diffusivity $\left(Ð=\bigoplus_{0} / 5\right)$ compared to the value used to model experimentally observed permeance $\left(\bigoplus=\bigoplus_{0} / 50\right)$ where $\bigoplus_{0}$ is the diffusivity predicted by theory. $\left(\mathrm{MM} \$=10^{6} \$\right)$

The current membrane technology, thus, is not adequate for attractive performance in butane isomers separation due to the requirement of large area and/or low cost. However, a 10-fold improvement in permeation through these membranes brings down the required membrane area comparable to that used in currently operating zeolite membrane plants [13]. Accordingly, the incurred cost can be as high as $\$ 5,000 / \mathrm{m}^{2}$ which is also a reasonable estimate of the cost of zeolite membranes [5]. This 10-fold improvement in permeation which can be achieved by either improving membrane microstructure and/or by reducing membrane thickness makes these membranes very attractive from an industrial perspective.

\section{Conclusion}

A detailed adsorption-diffusion model of a zeolite membrane process was developed and applied for butane isomer separation. The effects of the support layer, sweep gas and 
concentration polarization were also included. The comparison of steady state flux and separation factors predicted by the model with the experimentally determined quantities suggests a discrepancy between diffusion in zeolite membranes and diffusion in zeolite crystals. We found that in order to obtain the experimentally observed permeance and separation factor by simulation, we have to decrease the butane diffusivity in MFI crystals by a factor of $50\left(\bigoplus=\bigoplus_{0} / 50\right)$. The scope of improvement in the performance of current membranes was

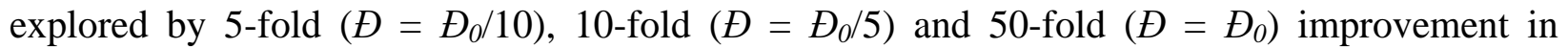
diffusivity observed in current membranes $\left(Ð=\bigoplus_{0} / 50\right)$. The results indicate that for up to a 10-fold improvement in diffusivity through the membrane, gains in membrane performance can be attained; for larger diffusivities, concentration polarization effects become significant and further improvement in membrane performance is not possible. We envision that this 10-fold improvement in diffusivity $\left(\bigoplus=\bigoplus_{0} / 5\right)$ can be achieved by reducing pore blockages in the intergrown membranes or, equivalently, its effect on performance can be achieved by reducing the membrane thickness from the currently achieved $\sim 500 \mathrm{~nm}$ to $50 \mathrm{~nm}$ or less.

Process simulations based on the detailed model for permeation through the membrane combined with a plug flow model along the length of the membrane, were also performed. Promising design options were determined to carry out butane isomer separation at industrial scale and compared to the current distillation technique. A single-stage membrane process was found to be inadequate as the purity is $\sim 2 \%$ lower as compared to the one achieved by distillation. A two stage membrane process, although matches the distillation performance, requires prohibitively large membrane area. Moreover, replacing distillation completely by membranes does not leverage the existing capital infrastructure. Therefore, a hybrid membrane-distillation process, which exploits the advantages of both processes was examined and found to be energy efficient and economically attractive. A series hybrid process, which is expected to be easy to retrofit and control, was proposed for this separation. With a 10-fold improvement in permeance as compared to that in current state-of-the-art ceramic supported MFI membranes, payback 
period of 3 years can be achieved with installed membrane cost of up to $\$ 5,000 / \mathrm{m}^{2}$. Alternatively, the same payback period can be achieved by the current technology if manufacturing improvements bring the membrane cost down to $\$ 500 / \mathrm{m}^{2}$.

\section{Acknowledgements:}

Support was provided by the Department of Energy's ARPAE program (Award number DE- AR0000338 (0670-3240)) and U.S. Department of Energy, Office of Basic Energy Sciences, Division of Chemical Sciences, Geosciences and Biosciences (Award DE-FG02-12ER16362). M.T. acknowledges the generous support provided by the Amundson Chair fund at the University of Minnesota. 
[1] J. Caro, M. Noack, P. Kölsch, and R. Schäfer. Zeolite membranes-state of their development and perspective. Microporous and Mesoporous Materials, 38 (2000) 3.

[2] J. Caro, M. Noack. Zeolite membranes-recent developments and progress. Microporous and Mesoporous Materials, 115 (2008) 215.

[3] S. Wee, C. Tye, and S. Bhatia. Membrane separation process - pervaporation through zeolite membrane. Separation and Purification Technology, 63 (2008) 500.

[4] M. Tsapatsis. Toward high-throughput zeolite membranes. Science, 334 (2011) 767.

[5] J. Gascon, F. Kapteijn, B. Zornoza, V. Sebastián, C. Casado, and J. Coronas. Practical approach to zeolitic membranes and coatings: state of the art, opportunities, barriers, and future perspectives. Chemistry of Materials, 24 (2012) 2829.

[6] Z. Lai, G. Bonilla, I. Diaz, J.G. Nery, K. Sujaoti, M.A. Amat, et al. Microstructural optimization of a zeolite membrane for organic vapor separation. Science, 300 (2003) 456.

[7] Y. Li, W. Yang. Microwave synthesis of zeolite membranes: a review. J.Membr.Sci., 316 (2008) 3.

[8] M. Yu, R.D. Noble, and J.L. Falconer. Zeolite membranes: microstructure characterization and permeation mechanisms. Acc.Chem.Res., 44 (2011) 1196.

[9] J.A. Stoeger, J. Choi, and M. Tsapatsis. Rapid thermal processing and separation performance of columnar MFI membranes on porous stainless steel tubes. Energy \& Environmental Science, 4 (2011) 3479.

[10] K. Varoon, X. Zhang, B. Elyassi, D.D. Brewer, M. Gettel, S. Kumar, et al. Dispersible exfoliated zeolite nanosheets and their application as a selective membrane. Science, 334 (2011) 72 .

[11] T.C.T. Pham, T.H. Nguyen, and K.B. Yoon. Gel-Free Secondary Growth of Uniformly Oriented Silica MFI Zeolite Films and Application for Xylene Separation. Angewandte Chemie International Edition, 52 (2013) 8693.

[12] Y. Peng, H. Lu, Z. Wang, and Y. Yan. Microstructural optimization of MFI-type zeolite membranes for ethanol-water separation. Journal of Materials Chemistry A, 2 (2014) 16093.

[13] N. Rangnekar, N. Mittal, B. Elyassi, J. Caro, and M. Tsapatsis. Zeolite membranes-a review and comparison with MOFs. Chem.Soc.Rev., 44 (2015) 7128.

[14] N. Kosinov, J. Gascon, F. Kapteijn, and E.J. Hensen. Recent developments in zeolite membranes for gas separation. J.Membr.Sci., 499 (2016) 65.

[15] T.C. Bowen, R.D. Noble, and J.L. Falconer. Fundamentals and applications of pervaporation through zeolite membranes. J.Membr.Sci., 245 (2004) 1.

[16] D. Korelskiy, T. Leppäjärvi, H. Zhou, M. Grahn, J. Tanskanen, and J. Hedlund. High flux MFI membranes for pervaporation. J.Membr.Sci., 427 (2013) 381. 
[17] B. Huang, Q. Liu, J. Caro, and A. Huang. Iso-butanol dehydration by pervaporation using zeolite LTA membranes prepared on 3-aminopropyltriethoxysilane-modified alumina tubes. J.Membr.Sci., 455 (2014) 200.

[18] B. Elyassi, M.Y. Jeon, M. Tsapatsis, K. Narasimharao, S.N. Basahel, and S. Al-Thabaiti. Ethanol/Water Mixture Pervaporation Performance of b-oriented Silicalite-1 Membranes Made by Gel-Free Secondary Growth. AIChE J., (2015).

[19] J. Coronas, R.D. Noble, and J.L. Falconer. Separations of $\mathrm{C}_{4}$ and $\mathrm{C}_{6}$ isomers in ZSM-5 tubular membranes. Ind Eng Chem Res, 37 (1998) 166.

[20] T. Matsufuji, N. Nishiyama, M. Matsukata, and K. Ueyama. Separation of butane and xylene isomers with MFI-type zeolitic membrane synthesized by a vapor-phase transport method. J.Membr.Sci., 178 (2000) 25.

[21] S. Nair, Z. Lai, V. Nikolakis, G. Xomeritakis, G. Bonilla, and M. Tsapatsis. Separation of close-boiling hydrocarbon mixtures by MFI and FAU membranes made by secondary growth. Microporous and Mesoporous Materials, 48 (2001) 219.

[22] T. Lee, J. Choi, and M. Tsapatsis. On the performance of c-oriented MFI zeolite Membranes treated by rapid thermal processing. J.Membr.Sci., 436 (2013) 79.

[23] K.V. Agrawal, B. Topuz, T.C.T. Pham, Nguyen T. H., N. Sauer, N. Rangnekar, et al. Oriented MFI Membranes by GEL-Less Secondary Growth of Sub-100 nm MFI-Nanosheet Seed Layers. Adv Mater, (2015).

[24] M.A. Carreon, S. Li, J.L. Falconer, and R.D. Noble. Alumina-supported SAPO-34 membranes for $\mathrm{CO}_{2} / \mathrm{CH}_{4}$ separation. J.Am.Chem.Soc., 130 (2008) 5412.

[25] J.C. White, P.K. Dutta, K. Shqau, and H. Verweij. Synthesis of ultrathin zeolite Y membranes and their application for separation of carbon dioxide and nitrogen gases. Langmuir, 26 (2010) 10287.

[26] T. Tomita, K. Nakayama, and H. Sakai. Gas separation characteristics of DDR type zeolite membrane. Microporous and Mesoporous Materials, 68 (2004) 71.

[27] H. Zhou, D. Korelskiy, E. Sjöberg, and J. Hedlund. Ultrathin hydrophobic MFI membranes. Microporous and Mesoporous Materials, 192 (2014) 76.

[28] J. Xiao, J. Wei. Diffusion mechanism of hydrocarbons in zeolites-I. Theory. Chemical Engineering Science, 47 (1992) 1123.

[29] J. Xiao, J. Wei. Diffusion mechanism of hydrocarbons in zeolites-II. Analysis of experimental observations. Chemical Engineering Science, 47 (1992) 1143.

[30] J. Coronas, J. Santamaría. Separations using zeolite membranes. Sep.Purif.Methods, 28 (1999) 127.

[31] D.S. Sholl. Understanding macroscopic diffusion of adsorbed molecules in crystalline nanoporous materials via atomistic simulations. Acc.Chem.Res., 39 (2006) 403. 
[32] R. Krishna. Describing the diffusion of guest molecules inside porous structures. The Journal of Physical Chemistry C, 113 (2009) 19756.

[33] R. Krishna. Diffusion in porous crystalline materials. Chem.Soc.Rev., 41 (2012) 3099.

[34] J. Kärger, D.M. Ruthven, and D.N. Theodorou, Diffusion in Nanoporous Materials, , John Wiley \& Sons, 2012.

[35] van de Graaf, Jolinde M, F. Kapteijn, and J.A. Moulijn. Modeling permeation of binary mixtures through zeolite membranes. AIChE J., 45 (1999) 497.

[36] A.I. Skoulidas, D.S. Sholl, and R. Krishna. Correlation effects in diffusion of $\mathrm{CH}_{4} / \mathrm{CF}_{4}$ mixtures in MFI zeolite. A study linking MD simulations with the Maxwell-Stefan formulation. Langmuir, 19 (2003) 7977.

[37] T.Q. Gardner, J.L. Falconer, and R.D. Noble. Transient permeation of butanes through ZSM-5 and ZSM-11 zeolite membranes. AIChE J., 50 (2004) 2816.

[38] R. Krishna, J.M. van Baten. A simplified procedure for estimation of mixture permeances from unary permeation data. J.Membr.Sci., 367 (2011) 204.

[39] Y.F. Yeong, A.Z. Abdullah, A.L. Ahmad, and S. Bhatia. Separation of $p$-xylene from binary xylene mixture over silicalite-1 membrane: Experimental and modeling studies. Chemical Engineering Science, 66 (2011) 897.

[40] T. Leppäjärvi, I. Malinen, D. Korelskiy, J. Hedlund, and J. Tanskanen. Maxwell-Stefan Modeling of Ethanol and Water Unary Pervaporation through a High-Silica MFI Zeolite Membrane. Ind Eng Chem Res, 53 (2013) 323.

[41] S. Brandani, M. Jama, and D.M. Ruthven. Counterdiffusion of $p$-xylene/benzene and $p$ xylene/o-xylene in silicalite studied by the zero-length column technique. Ind Eng Chem Res, 39 (2000) 821.

[42] A.M. Tarditi, E.A. Lombardo, and A.M. Avila. Xylene permeation transport through composite Ba-ZSM-5/SS tubular membranes: Modeling the steady-state permeation. Ind Eng Chem Res, 47 (2008) 2377.

[43] R. Krishna, J.M. van Baten. Highlighting pitfalls in the Maxwell-Stefan modeling of wateralcohol mixture permeation across pervaporation membranes. J.Membr.Sci., 360 (2010) 476.

[44] R. Krishna, J.M. van Baten. Hydrogen bonding effects in adsorption of water- alcohol mixtures in zeolites and the consequences for the characteristics of the Maxwell- Stefan diffusivities. Langmuir, 26 (2010) 10854.

[45] R. Krishna, J.M. van Baten. Maxwell-Stefan modeling of slowing-down effects in mixed gas permeation across porous membranes. J.Membr.Sci., 383 (2011) 289.

[46] P. Bai, M. Tsapatsis, and J.I. Siepmann. Multicomponent adsorption of alcohols onto silicalite-1 from aqueous solution: isotherms, structural analysis, and assessment of ideal adsorbed solution theory. Langmuir, 28 (2012) 15566. 
[47] L. Lu, Y. Zhu, X. Wu, S. Wang, W. Cao, and X. Lu. Adsorption of $n$-butane/i-butane in Zeolites: Simulation and Theory Study. Sep.Sci.Technol., 49 (2014) 1215.

[48] S.K. Wirawan, D. Creaser, J. Lindmark, J. Hedlund, I.M. Bendiyasa, and W.B. Sediawan. $\mathrm{H}_{2} / \mathrm{CO}_{2}$ permeation through a silicalite-1 composite membrane. J.Membr.Sci., 375 (2011) 313.

[49] J. Shao, Z. Zhan, J. Li, Z. Wang, K. Li, and Y. Yan. Zeolite NaA membranes supported on alumina hollow fibers: effect of support resistances on pervaporation performance. J.Membr.Sci., 451 (2014) 10.

[50] R. Krishna, L. Van den Broeke. The Maxwell-Stefan description of mass transport across zeolite membranes. The Chemical Engineering Journal and the Biochemical Engineering Journal, 57 (1995) 155.

[51] R. Krishna, D. Paschek. Permeation of hexane isomers across ZSM-5 zeolite membranes. Ind Eng Chem Res, 39 (2000) 2618.

[52] van de Graaf, Jolinde M, E. van der Bijl, A. Stol, F. Kapteijn, and J.A. Moulijn. Effect of operating conditions and membrane quality on the separation performance of composite silicalite-1 membranes. Ind Eng Chem Res, 37 (1998) 4071.

[53] J.G. Martinek, T.Q. Gardner, R.D. Noble, and J.L. Falconer. Modeling transient permeation of binary mixtures through zeolite membranes. Ind Eng Chem Res, 45 (2006) 6032.

[54] H. Li, U. Schygulla, J. Hoffmann, P. Niehoff, K. Haas-Santo, and R. Dittmeyer. Experimental and modeling study of gas transport through composite ceramic membranes. Chemical Engineering Science, 108 (2014) 94.

[55] van de Graaf, Jolinde M, F. Kapteijn, and J.A. Moulijn. Methodological and operational aspects of permeation measurements on silicalite-1 membranes. J.Membr.Sci., 144 (1998) 87.

[56] K. Kusakabe, T. Kuroda, and S. Morooka. Separation of carbon dioxide from nitrogen using ion-exchanged faujasite-type zeolite membranes formed on porous support tubes. J.Membr.Sci., 148 (1998) 13.

[57] A.M. Avila, H.H. Funke, Y. Zhang, J.L. Falconer, and R.D. Noble. Concentration polarization in SAPO-34 membranes at high pressures. J.Membr.Sci., 335 (2009) 32.

[58] F. Kapteijn, J. Moulijn, and R. Krishna. The generalized Maxwell-Stefan model for diffusion in zeolites:: sorbate molecules with different saturation loadings. Chemical Engineering Science, 55 (2000) 2923.

[59] R. Krishna, J. Van Baten. Diffusion of hydrocarbon mixtures in MFI zeolite: Influence of intersection blocking. Chem.Eng.J., 140 (2008) 614.

[60] X. Feng, R.Y. Huang. Concentration polarization in pervaporation separation processes. J.Membr.Sci., 92 (1994) 201.

[61] http://www.transparencymarketresearch.com/butane-market.html. 
[62] R. Krishna, J. Wesselingh. The Maxwell-Stefan approach to mass transfer. Chemical Engineering Science, 52 (1997) 861.

[63] R. Krishna, R. Baur. Modelling issues in zeolite based separation processes. Separation and Purification Technology, 33 (2003) 213.

[64] R. Krishna. The Maxwell-Stefan description of mixture diffusion in nanoporous crystalline materials. Microporous and Mesoporous Materials, 185 (2014) 30.

[65] F.J. Keil, R. Krishna, and M. Coppens. Modeling of diffusion in zeolites. Reviews in Chemical Engineering, 16 (2000) 71.

[66] http://www.iza-structure.org/databases/.

[67] E.N. Fuller, P.D. Schettler, and J.C. Giddings. New method for prediction of binary gasphase diffusion coefficients. Industrial \& Engineering Chemistry, 58 (1966) 18.

[68] A.I. Skoulidas, D.S. Sholl. Transport diffusivities of $\mathrm{CH}_{4}, \mathrm{CF}_{4}, \mathrm{He}, \mathrm{Ne}, \mathrm{Ar}$, $\mathrm{Xe}$, and $\mathrm{SF}_{6}$ in silicalite from atomistic simulations. The Journal of Physical Chemistry B, 106 (2002) 5058.

[69] R. Krishna, J. Van Baten. Insights into diffusion of gases in zeolites gained from molecular dynamics simulations. Microporous and Mesoporous Materials, 109 (2008) 91.

[70] F. Kapteijn, W. Bakker, J. Van de Graaf, G. Zheng, J. Poppe, and J. Moulijn. Permeation and separation behaviour of a silicalite-1 membrane. Catalysis Today, 25 (1995) 213.

[71] S. Bhattacharya, S. Hwang. Concentration polarization, separation factor, and Peclet number in membrane processes. J.Membr.Sci., 132 (1997) 73.

[72] W.M. Deen, Analysis of Transport Phenomena, Topics in Chemical Engineering, , Oxford University Press, New York, 1998.

[73] A.H.P. Skelland, Diffusional mass transfer, , Wiley New York, 1974.

[74] S. Kakaç, R.K. Shah, and W. Aung, Handbook of single-phase convective heat transfer, , Wiley New York et al., 1987.

[75] H. Stach, U. Lohse, H. Thamm, and W. Schirmer. Adsorption equilibria of hydrocarbons on highly dealuminated zeolites. Zeolites, 6 (1986) 74.

[76] R.E. Richards, L.V. Rees. Sorption and packing of n-alkane molecules in ZSM-5. Langmuir, 3 (1987) 335 .

[77] M.S. Sun, D. Shah, H.H. Xu, and O. Talu. Adsorption equilibria of $\mathrm{C}_{1}$ to $\mathrm{C}_{4}$ Alkanes, $\mathrm{CO}_{2}$, and $\mathrm{SF}_{6}$ on silicalite. The Journal of Physical Chemistry B, 102 (1998) 1466.

[78] W. Zhu, J. Van de Graaf, L. Van den Broeke, F. Kapteijn, and J. Moulijn. TEOM: A unique technique for measuring adsorption properties. Light alkanes in silicalite-1. Ind Eng Chem Res, 37 (1998) 1934. 
[79] W. Zhu, F. Kapteijn, and J. Moulijn. Adsorption of light alkanes on silicalite-1: Reconciliation of experimental data and molecular simulations. Physical Chemistry Chemical Physics, 2 (2000) 1989.

[80] H. Abdul-Rehman, M. Hasanain, and K. Loughlin. Quaternary, ternary, binary, and pure component sorption on zeolites. 1. Light alkanes on Linde S-115 silicalite at moderate to high pressures. Ind Eng Chem Res, 29 (1990) 1525.

[81] R.L. June, A.T. Bell, and D.N. Theodorou. Prediction of low occupancy sorption of alkanes in silicalite. J.Phys.Chem., 94 (1990) 1508.

[82] B. Smit, J. Siepmann. Computer simulations of the energetics and siting of $n$-alkanes in zeolites. J.Phys.Chem., 98 (1994) 8442.

[83] E.J. Maginn, A.T. Bell, and D.N. Theodorou. Sorption thermodynamics, siting, and conformation of long $n$-alkanes in silicalite as predicted by configurational-bias Monte Carlo integration. J.Phys.Chem., 99 (1995) 2057.

[84] T. Vlugt, W. Zhu, F. Kapteijn, J. Moulijn, B. Smit, and R. Krishna. Adsorption of linear and branched alkanes in the zeolite silicalite-1. J.Am.Chem.Soc., 120 (1998) 5599.

[85] T. Vlugt, R. Krishna, and B. Smit. Molecular simulations of adsorption isotherms for linear and branched alkanes and their mixtures in silicalite. The Journal of Physical Chemistry B, 103 (1999) 1102.

[86] H. Thamm, H. Stach, and W. Fiebig. Calorimetric study of the absorption of $n$-butane and but-l-ene on a highly dealuminated Y-type zeolite and on silicalite. Zeolites, 3 (1983) 95.

[87] H. Thamm. Adsorption site heterogeneity in silicalite: a calorimetric study. Zeolites, 7 (1987) 341.

[88] R. Krishna, D. Paschek. Separation of hydrocarbon mixtures using zeolite membranes: a modelling approach combining molecular simulations with the Maxwell-Stefan theory. Separation and Purification Technology, 21 (2000) 111.

[89] C. Chmelik, L. Heinke, J. van Baten, and R. Krishna. Diffusion of $n$-butane/iso-butane mixtures in silicalite-1 investigated using infrared (IR) microscopy. Microporous and Mesoporous Materials, 125 (2009) 11.

[90] T. Titze, C. Chmelik, J. Kärger, J.M. Van Baten, and R. Krishna. Uncommon synergy between adsorption and diffusion of hexane isomer mixtures in MFI zeolite induced by configurational entropy effects. The Journal of Physical Chemistry C, 118 (2014) 2660.

[91] A. Myers, J.M. Prausnitz. Thermodynamics of mixed-gas adsorption. AIChE J., 11 (1965) 121.

[92] K.P. Datema, C.J. den Ouden, W.D. Ylstra, H.P. Kuipers, M.F. Post, and J. Kärger. Fouriertransform pulsed-field-gradient ${ }^{1} \mathrm{H}$ nuclear magnetic resonance investigation of the diffusion of 
light $n$-alkanes in zeolite ZSM-5. Journal of the Chemical Society, Faraday Transactions, 87 (1991) 1935.

[93] W. Heink, J. Kärger, H. Pfeifer, K.P. Datema, and A.K. Nowak. High-temperature pulsed field gradient nuclear magnetic resonance self-diffusion measurements of $n$-alkanes in MFl-type zeolites. Journal of the Chemical Society, Faraday Transactions, 88 (1992) 3505.

[94] A. Pampel, M. Fernandez, D. Freude, and J. Kärger. New options for measuring molecular diffusion in zeolites by MAS PFG NMR. Chemical Physics Letters, 407 (2005) 53.

[95] S. Brandani, J. Caro, H. Jobic, J. Kärger, C. Krause, and R. Staudt. Diffusion of $n$-alkanes in zeolites: the benefit of observation over different length scales. Studies in Surface Science and Catalysis, 170 (2007) 981.

[96] M. Fernandez, J. Kärger, D. Freude, A. Pampel, J.M. van Baten, and R. Krishna. Mixture diffusion in zeolites studied by MAS PFG NMR and molecular simulation. Microporous and Mesoporous Materials, 105 (2007) 124.

[97] K. Banas, F. Brandani, D.M. Ruthven, F. Stallmach, and J. Kärger. Combining macroscopic and microscopic diffusion studies in zeolites using NMR techniques. Magn.Reson.Imaging, 23 (2005) 227.

[98] H. Jobic. Diffusion of linear and branched alkanes in ZSM-5. A quasi-elastic neutron scattering study. Journal of Molecular Catalysis A: Chemical, 158 (2000) 135.

[99] B. Millot, A. Méthivier, H. Jobic, H. Moueddeb, and M. Bée. Diffusion of isobutane in ZSM-5 zeolite: A comparison of quasi-elastic neutron scattering and supported membrane results. The Journal of Physical Chemistry B, 103 (1999) 1096.

[100] A. Chiang, A. Dixon, and Y. Ma. The determination of zeolite crystal diffusivity by gas chromatography-II. Experimental. Chemical Engineering Science, 39 (1984) 1461.

[101] J.R. Hufton, R.P. Danner. Chromatographic study of alkanes in silicalite: transport properties. AIChE J., 39 (1993) 962.

[102] T. Nijhuis, L. Van den Broeke, M. Linders, J. Van de Graaf, F. Kapteijn, M. Makkee, et al. Measurement and modeling of the transient adsorption, desorption and diffusion processes in microporous materials. Chemical Engineering Science, 54 (1999) 4423.

[103] T. Nijhuis, L. Van den Broeke, M. Linders, M. Makkee, F. Kapteijn, and J. Moulijn. Modeling of the transient sorption and diffusion processes in microporous materials at low pressure. Catalysis Today, 53 (1999) 189.

[104] J.R. Hufton, D.M. Ruthven. Diffusion of light alkanes in silicalite studied by the zero length column method. Ind Eng Chem Res, 32 (1993) 2379.

[105] M. Jiang, M. Eic, S. Miachon, J. Dalmon, and M. Kocirik. Diffusion of n-butane, isobutane and ethane in a MFI-zeolite membrane investigated by gas permeation and ZLC measurements. Separation and Purification Technology, 25 (2001) 287. 
[106] M. Jiang, M. Eić. Transport properties of ethane, butanes and their binary mixtures in MFItype zeolite and zeolite-membrane samples. Adsorption, 9 (2003) 225.

[107] W. Zhu, A. Malekian, M. Eić, F. Kapteijn, and J. Moulijn. Concentration-dependent diffusion of isobutane in silicalite-1 studied with the ZLC technique. Chemical Engineering Science, 59 (2004) 3827.

[108] A.P. Guimarães, A. Möller, R. Staudt, D.C. de Azevedo, S.M. Lucena, and C.L. Cavalcante Jr. Diffusion of linear paraffins in silicalite studied by the ZLC method in the presence of $\mathrm{CO}_{2}$. Adsorption, 16 (2010) 29.

[109] D.T. Hayhurst, A.R. Paravar. Diffusion of $\mathrm{C}_{1}$ to $\mathrm{C}_{5}$ normal paraffins in silicalite. Zeolites, 8 (1988) 27.

[110] D. Shah, S. Chokchai-Acha, and D. Hayhurst. Measurements of transport rates of $\mathrm{C}_{4}$ hydrocarbons across a single-crystal silicalite membrane. Journal of the Chemical Society, Faraday Transactions, 89 (1993) 3161.

[111] M.S. Sun, O. Talu, and D.B. Shah. Diffusion measurements through embedded zeolite crystals. AIChE J., 42 (1996) 3001.

[112] O. Talu, M.S. Sun, and D.B. Shah. Diffusivities of $n$-alkanes in silicalite by steady-state single-crystal membrane technique. AIChE J., 44 (1998) 681.

[113] O. Geier, S. Vasenkov, E. Lehmann, J. Kärger, U. Schemmert, R. Rakoczy, et al. Interference microscopy investigation of the influence of regular intergrowth effects in MFI-type zeolites on molecular uptake. The Journal of Physical Chemistry B, 105 (2001) 10217.

[114] P. Kortunov, S. Vasenkov, C. Chmelik, J. Kärger, D.M. Ruthven, and J. Wloch. Influence of defects on the external crystal surface on molecular uptake into MFI-type zeolites. Chemistry of Materials, 16 (2004) 3552.

[115] C. Chmelik, P. Kortunov, S. Vasenkov, and J. Kärger. Internal transport resistances and their influence on diffusion in zeolites as traced by microscopic measuring techniques. Adsorption, 11 (2005) 455.

[116] C. Chmelik, A. Varma, L. Heinke, D.B. Shah, J. Kärger, F. Kremer, et al. Effect of surface modification on uptake rates of isobutane in MFI crystals: An infrared microscopy study. Chemistry of Materials, 19 (2007) 6012.

[117] D. Shen, L.V. Rees, J. Caro, M. Bülow, B. Zibrowius, and H. Jobic. Diffusion of C4 hydrocarbons in silicalite-1. Journal of the Chemical Society, Faraday Transactions, 86 (1990) 3943.

[118] D. Shen, L.V. Rees. Adsorption and diffusion of $n$-butane and 2-butyne in silicalite-I. Zeolites, 11 (1991) 684. 
[119] A. Möller, A.P. Guimaraes, R. Gläser, and R. Staudt. Uptake-curves for the determination of diffusion coefficients and sorption equilibria for $\mathrm{n}$-alkanes on zeolites. Microporous and Mesoporous Materials, 125 (2009) 23.

[120] S.J. Goodbody, K. Watanabe, D. MacGowan, J.P. Walton, and N. Quirke. Molecular simulation of methane and butane in silicalite. Journal of the Chemical Society, Faraday Transactions, 87 (1991) 1951.

[121] R.L. June, A.T. Bell, and D.N. Theodorou. Molecular dynamics studies of butane and hexane in silicalite. J.Phys.Chem., 96 (1992) 1051.

[122] E.J. Maginn, A.T. Bell, and D.N. Theodorou. Dynamics of long $n$-alkanes in silicalite: A hierarchical simulation approach. J.Phys.Chem., 100 (1996) 7155.

[123] R.C. Runnebaum, E.J. Maginn. Molecular dynamics simulations of alkanes in the zeolite silicalite: Evidence for resonant diffusion effects. The Journal of Physical Chemistry B, 101 (1997) 6394.

[124] A. Bouyermaouen, A. Bellemans. Molecular dynamics simulation of the diffusion of $n$ butane and $i$-butane in silicalite. J.Chem.Phys., 108 (1998) 2170.

[125] L.N. Gergidis, D.N. Theodorou. Molecular dynamics simulation of $n$-butane-methane mixtures in silicalite. The Journal of Physical Chemistry B, 103 (1999) 3380.

[126] D. Paschek, R. Krishna. Monte Carlo simulations of sorption and diffusion of isobutane in silicalite. Chemical Physics Letters, 342 (2001) 148.

[127] C. Chmelik, L. Heinke, J. Kärger, W. Schmidt, D. Shah, J. Van Baten, et al. Inflection in the loading dependence of the Maxwell-Stefan diffusivity of iso-butane in MFI zeolite. Chemical Physics Letters, 459 (2008) 141.

[128] A.J. O'Malley, C.R.A. Catlow, M. Monkenbusch, and H. Jobic. Diffusion of Isobutane in Silicalite: A Neutron Spin-Echo and Molecular Dynamics Simulation Study. The Journal of Physical Chemistry C, 119 (2015) 26999.

[129] F. Kapteijn, W.J. Bakker, G. Zheng, and J.A. Moulijn. Temperature-and occupancydependent diffusion of n-butane through a silicalite-1 membrane. Microporous Materials, 3 (1994) 227.

[130] W.J. Bakker, Van Den Broeke, Leo JP, F. Kapteijn, and J.A. Moulijn. Temperature dependence of one-component permeation through a silicalite-1 membrane. AIChE J., 43 (1997) 2203.

[131] van de Graaf, Jolinde M, F. Kapteijn, and J.A. Moulijn. Diffusivities of light alkanes in a silicalite-1 membrane layer. Microporous and Mesoporous Materials, 35 (2000) 267.

[132] W.J. Bakker, F. Kapteijn, J. Poppe, and J.A. Moulijn. Permeation characteristics of a metal-supported silicalite-1 zeolite membrane. J.Membr.Sci., 117 (1996) 57. 
[133] Z. Vroon, K. Keizer, M. Gilde, H. Verweij, and A. Burggraaf. Transport properties of alkanes through ceramic thin zeolite MFI membranes. J.Membr.Sci., 113 (1996) 293.

[134] A. Burggraaf, Z. Vroon, K. Keizer, and H. Verweij. Permeation of single gases in thin zeolite MFI membranes. J.Membr.Sci., 144 (1998) 77.

[135] A. Burggraaf. Single gas permeation of thin zeolite (MFI) membranes: theory and analysis of experimental observations. J.Membr.Sci., 155 (1999) 45.

[136] T.Q. Gardner, J.L. Falconer, and R.D. Noble. Adsorption and diffusion properties of zeolite membranes by transient permeation. Desalination, 149 (2002) 435.

[137] T.Q. Gardner, J.B. Lee, R.D. Noble, and J.L. Falconer. Adsorption and diffusion properties of butanes in ZSM-5 zeolite membranes. Ind Eng Chem Res, 41 (2002) 4094.

[138] V.A. Tuan, J.L. Falconer, and R.D. Noble. Alkali-free ZSM-5 membranes: preparation conditions and separation performance. Ind Eng Chem Res, 38 (1999) 3635.

[139] Process Systems Enterprise, gPROMS, www.psenterprise.com/gproms, 1997-2015.

[140] H. Jeong, Z. Lai, M. Tsapatsis, and J.C. Hanson. Strain of MFI crystals in membranes: An in situ synchrotron X-ray study. Microporous and Mesoporous Materials, 84 (2005) 332.

[141] N. Rangnekar, M. Shete, K.V. Agrawal, B. Topuz, P. Kumar, Q. Guo, et al. 2D zeolite coatings: Langmuir-Schaefer deposition of $3 \mathrm{~nm}$ thick MFI zeolite nanosheets. Angewandte Chemie International Edition, 127 (2015) 6671.

[142] G. Soave. Equilibrium constants from a modified Redlich-Kwong equation of state. Chemical Engineering Science, 27 (1972) 1197.

[143] J.F. Ely, H. Hanley. Prediction of transport properties. 1. Viscosity of fluids and mixtures. Industrial \& Engineering Chemistry Fundamentals, 20 (1981) 323.

[144] K.T. Klemola, J.K. Ilme. Distillation efficiencies of an industrial-scale $i$-butane/n-butane fractionator. Ind Eng Chem Res, 35 (1996) 4579.

[145] http://www.aspentech.com/products/engineering/aspen-plus/.

[146] J.M. Douglas, Conceptual design of chemical processes, , McGraw-Hill New York, 1988.

[147] R. Turton, R.C. Bailie, W.B. Whiting, and J.A. Shaeiwitz, Analysis, synthesis and design of chemical processes, , Pearson Education, 2008.

[148] S. Moganti, R.D. Noble, and C.A. Koval. Analysis of a membrane/distillation column hydrid process. J.Membr.Sci., 93 (1994) 31.

[149] T. Pettersen, K.M. Lien. Design of hybrid distillation and vapor permeation processes. J.Membr.Sci., 102 (1995) 21.

[150] W. Stephan, R.D. Noble, and C.A. Koval. Design methodology for a membrane/distillation column hybrid process. J.Membr.Sci., 99 (1995) 259. 
[151] T.G. Pressly, K.M. Ng. A break-even analysis of distillation-membrane hybrids. AIChE J., 44 (1998) 93.

[152] T. Pettersen, A. Argo, R.D. Noble, and C.A. Koval. Design of combined membrane and distillation processes. Separations Technology, 6 (1996) 175.

[153] I.K. Kookos. Optimal design of membrane/distillation column hybrid processes. Ind Eng Chem Res, 42 (2003) 1731.

[154] J.A. Caballero, I.E. Grossmann, M. Keyvani, and E.S. Lenz. Design of hybrid distillationvapor membrane separation systems. Ind Eng Chem Res, 48 (2009) 9151.

[155] J. Ploegmakers, A.R. Jelsma, A. Van der Ham, and K. Nijmeijer. Economic evaluation of membrane potential for ethylene/ethane separation in a retrofitted hybrid membrane-distillation plant using unisim design. Ind Eng Chem Res, 52 (2013) 6524. 
Adsorption at zeolite surface

(Real adsorption solution theory)

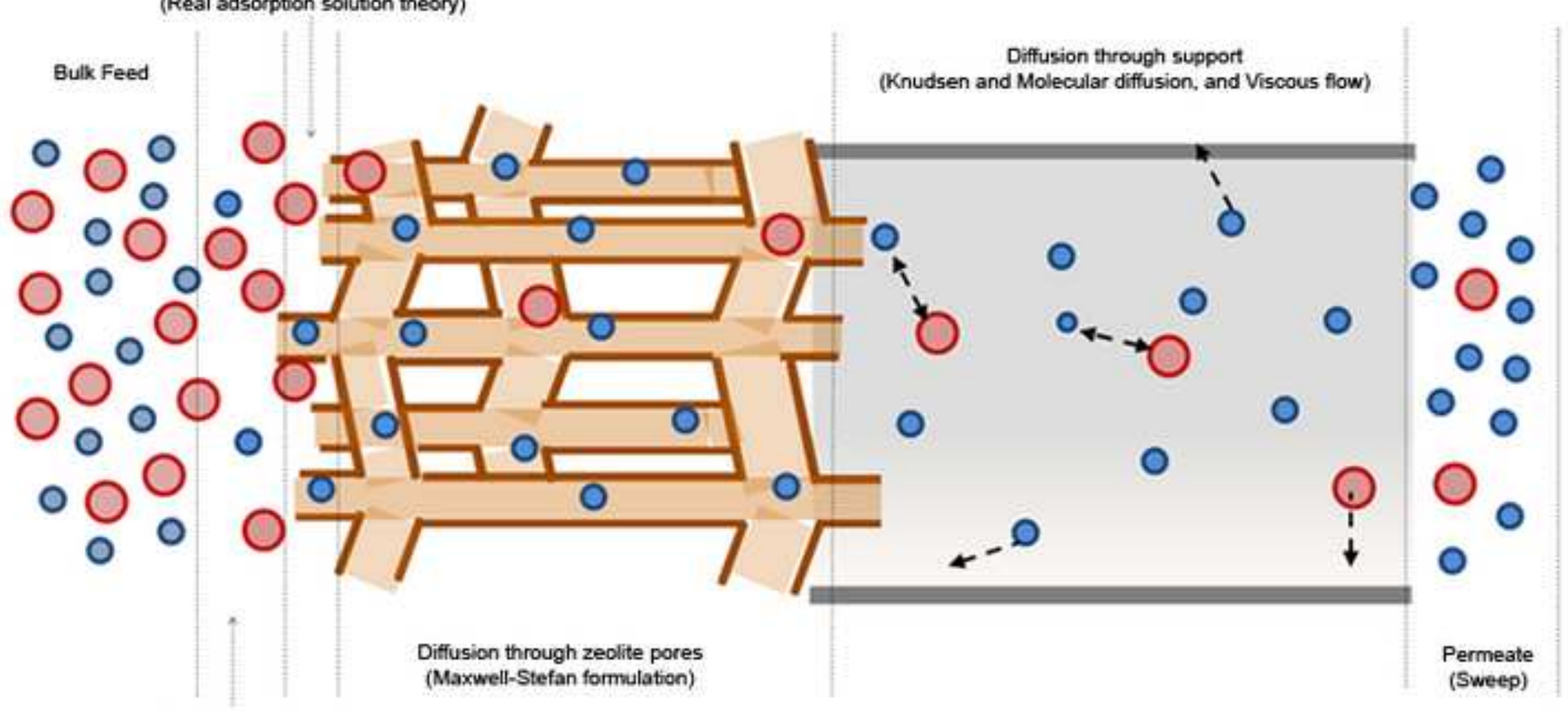

Boundary layer

(Concentration polarization) 